\title{
Prediction of subcooled flow boiling pressure drops in small circular tubes
}

\author{
Luca Gugliermetti ${ }^{1}$, Gianfranco Caruso ${ }^{1}$, Luca Saraceno ${ }^{2}$ \\ ${ }^{1}$ SAPIENZA, University of Rome - DIAEE, Department of Astronautical, Electrical and Energy \\ Engineering, Rome, ITALY \\ ${ }^{2}$ ENEA- Laboratory of Development of Chemical Processes and Thermofluidynamics, Rome, ITALY
}

\section{Abstract}

Two-phase pressure drops in a mini-tube, in transition flow and subcooled boiling, are analyzed in the present paper, with the support of an experimental data set provided by ENEA with their BO.E.MI.A. test section. The methodology can be applied to different fluids according to similarity criteria. Single phase, subcooled and saturated conditions have been analysed. The Reynolds number in the experiments was mainly in the transition zone between laminar and turbulent conditions, therefore a third order interpolation curve of the friction factor has been employed. The methodology is based on the model from Delhaye. The model considers the fluid properties, the energy, mass and momentum conservation equations to predict the ONB and OSV points and a hyperbolic function has been adopted to calculate the non-equilibrium vapor quality in the subcooled boiling region. The best agreement with the ENEA experimental data has been obtained using in the methodology the Chisholm correlation, with $83.59 \%$ of the predicted values with an error lower than $30 \%$.

Keywords: Subcooled flow boiling, pressure drops, transition flow

\section{INTRODUCTION}

Extreme engineering applications often require small high-performing solutions. For heating issues, micro-heat exchangers are widely used, as, for example, in the electronic chips cooling where high heat fluxes must be discharged over a small area. One of the simplest arrangements that can be used for the heat removal involves single-phase forced convection that is, however, limited in terms of efficiency. The higher heat transfer coefficients could be achieved only employing a phase transition, and subcooled flow boiling can be considered the best solution for small-scale heat removal equipment.

Due to the small hydraulic diameter used in mini- and micro-exchangers, excessive pressure drop is always a concern, since these devices are typically used in combination with pumps with limited 
pumping power capability. Another concern is the pressure oscillation due to hydrodynamic instabilities that can appear in subcooled boundaries, You et al. [1], and that can lead up to CHF, Caira et al. [2]. Thus, instabilities must be predicted and prevented to ensure safe operation and good cooling performance. A few published studies discuss pressure drop and hydrodynamic instability of flow boiling in mini/micro-tubes. These concerns are compounded when the fluid flow is in transition between laminar and turbulent flows, where there is no valid and established model.

Jacobi et al. [3] proposed a classification based on the physical size of the channels: micro-channels for a size range $1 \mu \mathrm{m}-100 \mu \mathrm{m}$, meso-channels for channel sizes from $100 \mu \mathrm{m}$ to $1.0 \mathrm{~mm}$, compact channels from $1.0 \mathrm{~mm}$ to $6.0 \mathrm{~mm}$ and, macro-channels for all channel sizes exceeding $6.0 \mathrm{~mm}$. Instead, Kandlikar et al. [4] proposed a classification based on flow considerations: conventional channels for hydraulic diameters of $3.0 \mathrm{~mm}$ or larger, mini-channels for hydraulic diameters of 200 $\mu \mathrm{m}$ to $3.0 \mathrm{~mm}$, micro-channels for hydraulic diameters smaller than $200 \mu \mathrm{m}$. The recommendations are valid for both single-phase and two-phase systems. Cheng and $\mathrm{Wu}$ [5] proposed criteria based on the Bond number $B d=g\left(\rho_{f}-\rho_{g}\right) D^{2} / \sigma$, to consider the properties of the fluid and, therefore, the gravity and surface tension effects: micro-channel, if $B d<0.05$ (significant effect of surface tension); mini-channel, if $0.05<B d<3.0$ (both gravity and surface tension are important); macro-channel, if $B d>3.0$ (surface tension has negligible effect).

Pressure drops in saturated flow boiling were largely analyzed at macro-scale, Ould Didi et al. [6] compared seven of the most quoted macro-scale methods in the literature to determinate frictional pressure drop on a 788 points database in two horizontal macro-scale test sections of 10.92 and 12.00 $\mathrm{mm}$ diameter for five fluorocarbon refrigerants. They found that the methods of Muller-Steinhagen and Heck [7] and Gronnerud [8] gave the best predictions. Ribatski el al. [9] compared twelve prediction methods and found as the most effective the macro-scale method proposed in [7]. However, they showed how none of the analyzed methods can be classified as a design tool for microscale tubes.

In micro-scale Zhang and Webb [10], Kuwahara et al. [11] obtained good predictions of their data for R134a by using the Friedel [12] correlation. Also, Lazarek and Black [13] studied the problem obtaining good forecasts by using a value of $C=30$ in the generalized Chisholm [14] and LockhartMartinelli [15] correlations. Along this direction, Qu and Mudawar [16], Lee and Mudawar [17] and Lee and Garimella [18] developed flow boiling pressure drop models based on their experimental data developed in microchannel heat sinks. Mishima and Hibiki [19] obtained reasonably good predictions for their frictional pressure drop data by correlating the Chisholm [14] parameter in the Lockhart-Martinelli [15] correlation as a function of the tube diameter. Bowers and Mudawar [20; 
21] analyzed flow boiling pressure drop of refrigerant R-113, using a homogenous equilibrium model, in both mini and micro-channel obtaining a good agreement. Two-phase hydrodynamic instabilities in parallel mini/micro-channels were addressed by Kandlikar et al. [22] and Hetsroni et al. [23]. Tran et al. [24] studied flow boiling pressure drop of three different refrigerants in single tubes and for a single rectangular channel. Kim and Mudawar [25] developed a model, using a database of 2378 experimental points, that takes into account six dimensionless parameters to calculate the LockhartMartinelli $C$ parameter.

Both macro-scale and micro-scale correlations have been used in the literature to develop models for heat transfer and pressure drops in mini-channels, and mainly in laminar or turbulent conditions. The pressure drops in a mini-channel in single and two-phase transition flow are analyzed in the present paper, with the support of experimental data provided by ENEA in their BO.E.MI.A. test section [26]. The main aim of the work is to provide a comprehensive methodology to predict pressure drops for small circular tubes, in transition flow and subcooled boiling condition, valid for many fluids according to similarity criteria, due to the lack of specific models in these conditions.

\section{THE BO.E.MI.A. EXPERIMENTAL FACILITY}

The BO.E.MI.A. experimental facility (BOiling Experiments in MIcrochannel Apparatus) was built at the ENEA Laboratory of Chemical and Thermo-Fluid Dynamic Processes for Energy. It consists of a tube of $1.016 \mathrm{~mm}$ (internal diameter) and wall thickness $0.57 \mathrm{~mm}$; two different total lengths have been used, 100 or $200 \mathrm{~mm}$ : The working fluid is the refrigerant FC-72 (perfluorohexane C6F14). The facility can operate at pressures up to 10 bar and a volumetric flowrate from 6 to $552 \mathrm{ml} / \mathrm{min}$. An upstream electrical preheater allows the inlet temperature setting up to saturation condition or to a planned subcooled degree. A counter-current tube-in-tube condenser, cooled by demineralized water, is placed downstream the section. Fig. 1 shows the facility scheme with the main components: 


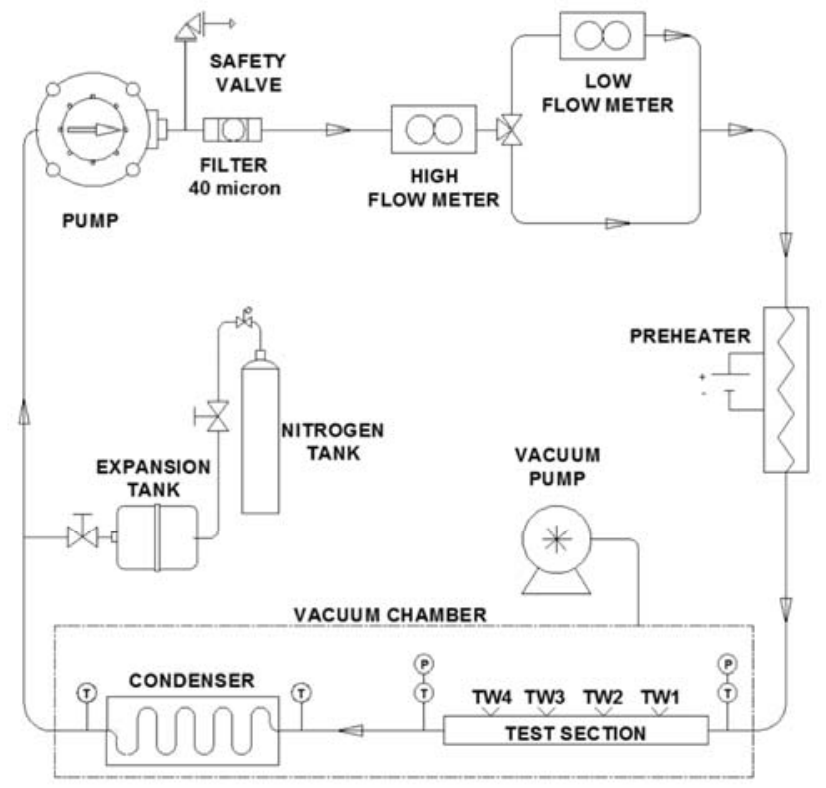

Fig. 1 - BO.E.MI.A. facility simplified layout

The test rig includes: pressure taps, thermocouples for bulk fluid temperature measurement, power supply and four wall thermocouples. $\mathrm{LH}_{\mathrm{H}}$ is the heated length, equal to $84 \mathrm{~mm}$ for the $200 \mathrm{~mm}$ length tube and $60 \mathrm{~mm}$ for the $100 \mathrm{~mm}$ tube. $\mathrm{L}_{\mathrm{p}}$ is the distance between the pressure sensors, equal to $96 \mathrm{~mm}$ and $70 \mathrm{~mm}$ for the $200 \mathrm{~mm}$ tube and the $100 \mathrm{~mm}$ tube, respectively. A constant power DC supply is used to heat uniformly the test section by Joule effect; the maximum heat flux generable along the channel is $150 \mathrm{~kW} / \mathrm{m}^{2}$. Axial conduction effects are negligible, as discussed in [26]. Fig. 2 schematically represent the layout of the heated channel in the facility.

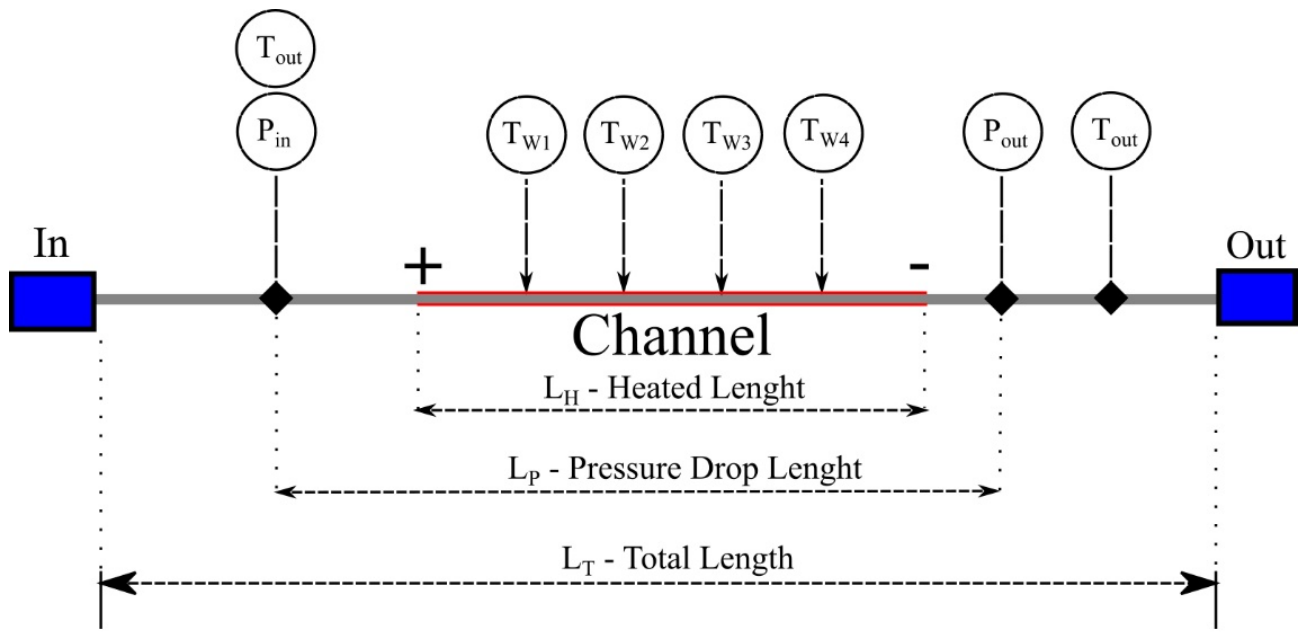

Fig. 2 - Test section layout

The instruments' uncertainties and the most significant calculated ones are presented in Tab. 1. The channel is horizontally oriented. Any further detail can be found in [26] and [27]. 
International Journal of Heat and Mass Transfer 115 (2017) 1074-1090

http://dx.doi.org/10.1016/j.ijheatmasstransfer.2017.07.126

102

\begin{tabular}{c|cc} 
Mass flow rate (high) & 0.15 & \% of Readings \\
\hline Mass flow rate (low) & 1 & $\%$ on F.S. \\
Diameter & 25 & $\mu \mathrm{m}$ \\
Temperature & 0.40 & ${ }^{\circ} \mathrm{C}$ \\
Pressure & 0.08 & $\%$ on F.S. \\
Differential pressure & 0.075 & \% of Calibrated Span \\
Electrical Power & $0.48-1.42$ & \% of Readings
\end{tabular}

Tab. 1 - Measurement uncertainties
103

104 Experimental tests were performed at a pressure of 3 and 4 bar, mass flux is in the range 415-1439 $105 \mathrm{Kg} / \mathrm{m}^{2} \mathrm{~s}$ and $1.5-181 \mathrm{~kW} / \mathrm{m}^{2}$ was the range of the applied heat flux. A total of 161 total pressure drop 106 107 108 109 110 data points (38 in single phase only, 63 up to subcooled flow boiling and 60 reaching saturated boiling condition) were collected for the $200-\mathrm{mm}$ tube and 141 data for the $100-\mathrm{mm}$ tube (41 in single phase, 76 with subcooled flow boiling and 24 up to saturated boiling), for a total of 302 data points, 79 of which in single phase condition, 139 up to subcooled flow boiling and 84 including saturated conditions also. Inlet subcooling was between 8.3 and $32.4^{\circ} \mathrm{C}$. Reynolds number was from 2500 to 4500 for the $200-\mathrm{mm}$ tube and between 2750 and 3600 for the $100 \mathrm{~mm}$ tube: thus the flow is always in transition conditions. The identification of single-phase, subcooled and saturated boiling points is based on the calculation of the "onset of nucleate boiling" point (described in Sect. 4) and the energy balance to evaluate the bulk saturation point and the saturation length. The test matrixes are shown in Tables 2 and 3 .

Two pressure transducers ( $0-25$ bar) on either side of the mini-tube provided the total pressure drop over the channel; a differential manometer (0-6.895 bar) was mounted in parallel to the transducers for extra precise differential pressure measurements, as reported in Saraceno et al. [26].

According to both Kandlikar et al. [4] criterion (diameter is $1 \mathrm{~mm}$ ) the experimental tube can be classified as a mini-channel. If the and Cheng and $\mathrm{Wu}$ [5] criterion is used, the Bond number is between 2.7 and 3.3, close to the upper boundary between mini-channel and macro-channel. 
International Journal of Heat and Mass Transfer 115 (2017) 1074-1090

http://dx.doi.org/10.1016/j.ijheatmasstransfer.2017.07.126

Tab. 2 - Test matrix for $200 \mathrm{~mm}$ tube

\begin{tabular}{|c|c|c|c|c|c|c|c|c|c|c|c|}
\hline Tests series & $T$ & $P$ & Mass flux & $q^{\prime \prime} \min$ & $q^{\prime \prime} \max$ & Total points & $\begin{array}{l}\text { Single } \\
\text { phase }\end{array}$ & $\begin{array}{c}\text { Up to } \\
\text { Subcooled } \\
\text { boiling }\end{array}$ & $\begin{array}{c}\text { Up to } \\
\text { Saturated } \\
\text { boiling }\end{array}$ & $\Delta T_{\text {sub,in }}$ & $\boldsymbol{R e}_{\text {in }}$ \\
\hline- & ${ }^{\circ} \mathrm{C}$ & Bar & $\mathrm{kg} / \mathrm{m}^{2} \mathrm{~s}$ & $\mathrm{~W} / \mathrm{m}^{2}$ & $\mathrm{~W} / \mathrm{m}^{2}$ & $n^{\circ}$ & $\mathrm{n}^{\circ}$ & $\mathrm{n}^{\circ}$ & $n^{\circ}$ & ${ }^{\circ} \mathrm{C}$ & - \\
\hline 1 & 84 & 3.08 & 1126 & 4357 & 98414 & 32 & 3 & 14 & 15 & 13.78 & 3250 \\
\hline 2 & 88 & 5.02 & 1234 & 4227 & 181562 & 32 & 19 & 11 & 2 & 32.42 & 3475 \\
\hline 3 & 87 & 4.08 & 1234 & 4297 & 170409 & 18 & 8 & 5 & 5 & 24.22 & 3450 \\
\hline 4 & 97 & 4.04 & 1030 & 3297 & 97900 & 13 & 1 & 5 & 7 & 9.12 & 3450 \\
\hline 5 & 97 & 4.05 & 925 & 3188 & 99653 & 15 & 1 & 5 & 9 & 9.22 & 3200 \\
\hline 6 & 98 & 4.04 & 824 & 3056 & 86153 & 17 & 2 & 5 & 10 & 9.02 & 2880 \\
\hline 7 & 84 & 3.05 & 1235 & 4143 & 71069 & 15 & 2 & 10 & 3 & 13.21 & 2500 \\
\hline 8 & 97 & 4.05 & 1439 & 7406 & 87896 & 8 & 1 & 3 & 4 & 9.06 & 4500 \\
\hline \multirow[t]{2}{*}{9} & 87 & 3.04 & 1132 & 4070 & 70838 & 11 & 1 & 5 & 5 & 8.32 & 3300 \\
\hline & & & & & Total & 161 & 38 & 63 & 60 & & \\
\hline
\end{tabular}

Tab. 3 - Test matrix for $100 \mathrm{~mm}$ tube

\begin{tabular}{|c|c|c|c|c|c|c|c|c|c|c|c|}
\hline Tests series & $T$ & $P$ & Mass flux & $q^{\prime \prime} \min$ & $q^{\prime \prime} \max$ & Total points & $\begin{array}{c}\text { Single } \\
\text { phase }\end{array}$ & $\begin{array}{c}\text { Up to } \\
\text { Subcooled } \\
\text { boiling }\end{array}$ & $\begin{array}{c}\text { Up to } \\
\text { Saturated } \\
\text { boiling }\end{array}$ & $\Delta T_{\text {sub,in }}$ & $\boldsymbol{R e}_{i n}$ \\
\hline - & ${ }^{\circ} \mathrm{C}$ & Bar & $\mathrm{Kg} / \mathrm{m}^{2} \mathbf{s}$ & $\mathrm{W} / \mathrm{m}^{2}$ & $\mathrm{~W} / \mathrm{m}^{2}$ & $\mathrm{n}^{\circ}$ & $\mathrm{n}^{\circ}$ & $\mathrm{n}^{\circ}$ & $\mathrm{n}^{\circ}$ & ${ }^{\circ} \mathrm{C}$ & - \\
\hline 1 & 65 & 3.04 & 1149 & 7685 & 76510 & 16 & 13 & 3 & 0 & 32.28 & 2750 \\
\hline 2 & 78 & 3.02 & 1131 & 7687 & 76510 & 16 & 6 & 10 & 0 & 19.74 & 3050 \\
\hline 3 & 85 & 3.07 & 1148 & 2501 & 47315 & 10 & 3 & 7 & 0 & 11.00 & 3350 \\
\hline 4 & 86 & 3.08 & 1139 & 7422 & 80253 & 17 & 3 & 12 & 2 & 13.21 & 3250 \\
\hline 5 & 86 & 3.09 & 1126 & 8718 & 127005 & 21 & 2 & 11 & 8 & 11.75 & 3250 \\
\hline 6 & 85 & 3.04 & 1032 & 1612 & 113401 & 25 & 3 & 11 & 11 & 12.60 & 2950 \\
\hline 7 & 91 & 4.03 & 1223 & 2923 & 116891 & 24 & 7 & 14 & 3 & 17.89 & 3600 \\
\hline \multirow[t]{2}{*}{8} & 93 & 4.01 & 1138 & 2286 & 57113 & 12 & 4 & 8 & 0 & 12.96 & 3500 \\
\hline & & & & & Total & 141 & 41 & 76 & 24 & & \\
\hline
\end{tabular}




\section{SIMILARITY CRITERIA}

An important issue in utilizing the available correlations is their applicability when different fluids are used. To overcome these difficulty, Delhaye et al. [28] developed some criteria based on the Kay and Nedderman [29] assumptions on enthalpy. These criteria may be applied both to models and correlations and they are useful to understand if the specific correlation is applicable regardless the fluid and the proprieties adopted. The similarity criteria can be summarized in the following requirements:

- Same channel shape: different shapes influence the boundary layers and the heat flux distribution along the channel.

- Same vapor to liquid density ratio at the respective pressures:

$$
\left(\frac{\rho_{v}}{\rho_{l}}\right)_{p(\text { fluid }(a))}=\left(\frac{\rho_{v}}{\rho_{l}}\right)_{p(\text { fluid }(b))}
$$

To avoid any difference in the volume occupied by every phase the ratio between the specific volume of the two phases should be the same at the saturation pressure.

- Same Weber number, to derive the equivalent mass flux G:

$$
W e \cong \frac{G^{2} D}{\sigma \rho_{l, s a t}}=>G_{f l u i d(b)}=\sqrt{\frac{W e_{\text {fluid }(a)} \sigma \rho_{l, s a t}}{D}}
$$

The inertia/surface tension ratio should be the same to grant the same film, droplet or bubbles dimension.

- Same Boiling Number, to calculate the equivalent heat flux $Q$ :

$$
B o \cong \frac{Q}{G H_{l v}}=>Q_{f l u i d(b)}=\frac{H_{l v, f l u i d(b)} \cdot Q_{f l u i d(a)} \cdot G_{f l u i d}(b)}{H_{l v, f l u i d(a)} \cdot G_{f l u i d}(a)}
$$

The Boiling number can be thought of as the ratio of the produced vapor mass flux to the total mass flux. A different mass of vapor generated can change the vapor distribution in the channel up to the thermal crisis.

- Same equilibrium quality, to calculate the equivalent inlet temperature:

$$
\begin{gathered}
x_{e q, \text { in }} \cong \frac{H_{l, \text { in }}-H_{l, \text { sat }}}{H_{l v}}=> \\
H(T)_{l, \text { in fluid (b) }}=H_{l, \text { sat fluid (b) }}+\frac{H_{l v, \text { fluid }(b)}}{H_{l v, \text { fluid }(a)}}\left(H_{l, \text { in }}-H_{l, \text { sat }}\right)_{\text {fluid }(a)}
\end{gathered}
$$

The use of the same equilibrium quality to calculate an equivalent inlet temperature is useful to grant the same energetic inlet condition for the fluid.

Wetting fluids, as FC-72, show a high thermal hysteresis in high subcooled condition at the inlet, see Fig. 3, as reported in the work of Celata et al. [30]. 
Due the limited literature concerning the use of FC-72, the similarity criteria have been largely adopted in this paper, to understand if a correlation is applicable to the BO.E.MI.A. experimental setup.

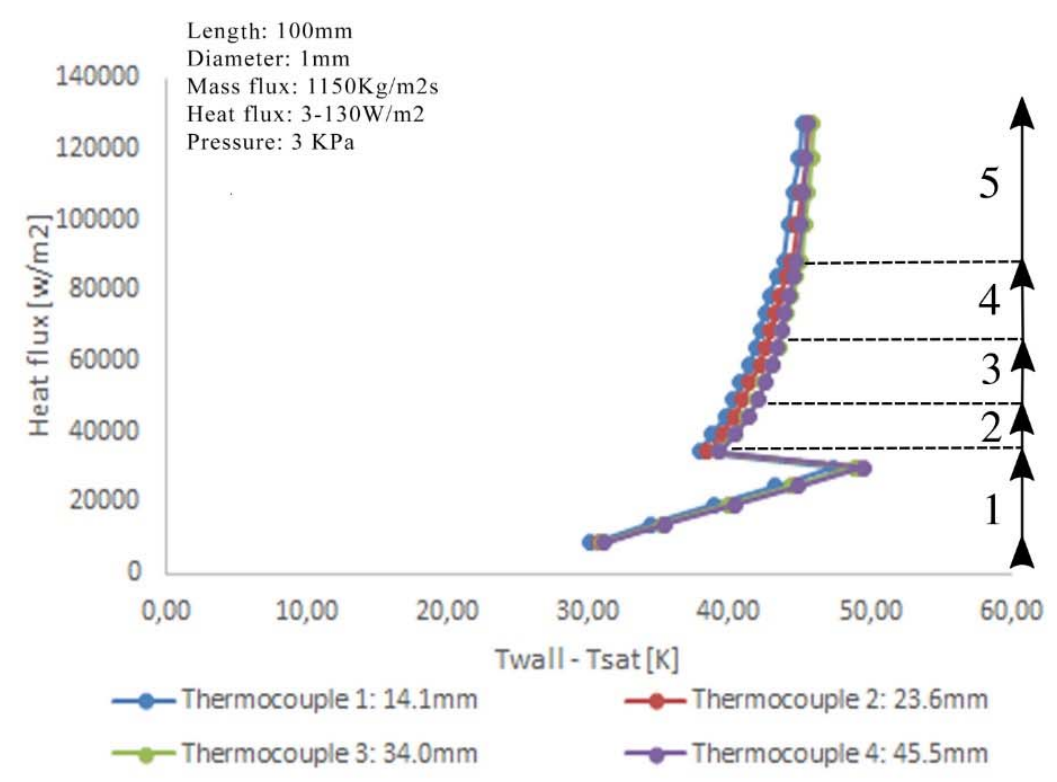

5 - Film

Boiling

4 - Transition

Boiling

3 - Fully Dev.

Nucl. Boiling

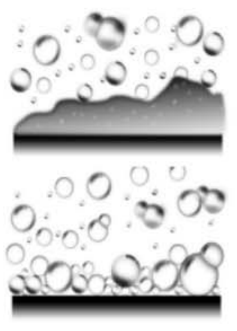

2 - Partial Nucl. Boiling

1 - Forced

Convection

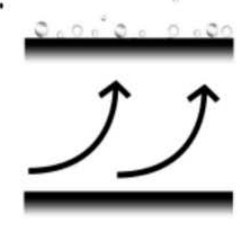

Fig. 3 - Heat flux vs wall superheating at $1150 \mathrm{Kg} / \mathrm{m}^{2} \mathrm{~s}$ on $100 \mathrm{~mm}$ tube, boiling phases

\section{SUBCOOLED BOUNDARIES CALCULATION}

Single phase forced convection ends when the first vapor bubbles appear at the first nucleation site at the ONB (Fig. 4). When a significant increase in the void fraction occurs, the fluid reaches the "onset of significant void" (OSV). Finally, saturated boiling starts when the whole mixture is in saturated conditions. Once defined ONB and OSV, it is possible to distinguish two regions in the subcooled zone: the partially developed boiling (PDB) region, delimited by the ONB and the OSV, and the fully developed boiling (FDB) region which is delimited by the OSV and the saturation point.

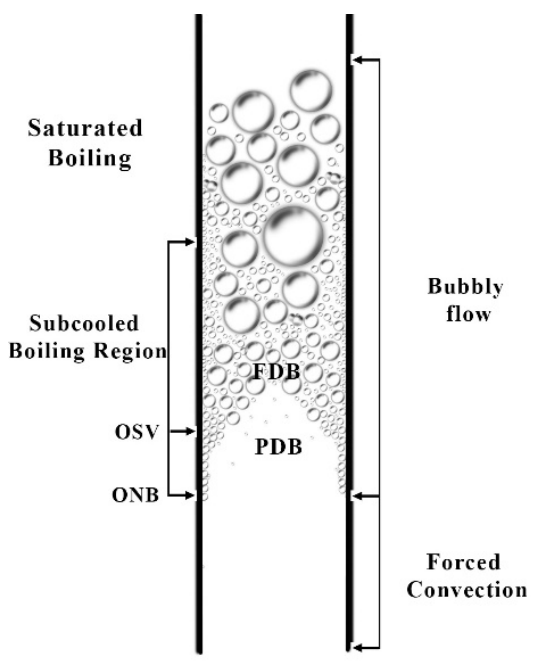

Fig. 4 - Subcooled flow boiling representation in a vertical channel 
173 The void fraction increases slightly from the ONB to the OSV and it increases much faster in the 174 FDB region. The wall temperature increases linearly in single phase flow and remains almost constant 175 in the boiling region, as shown in Fig. 5.

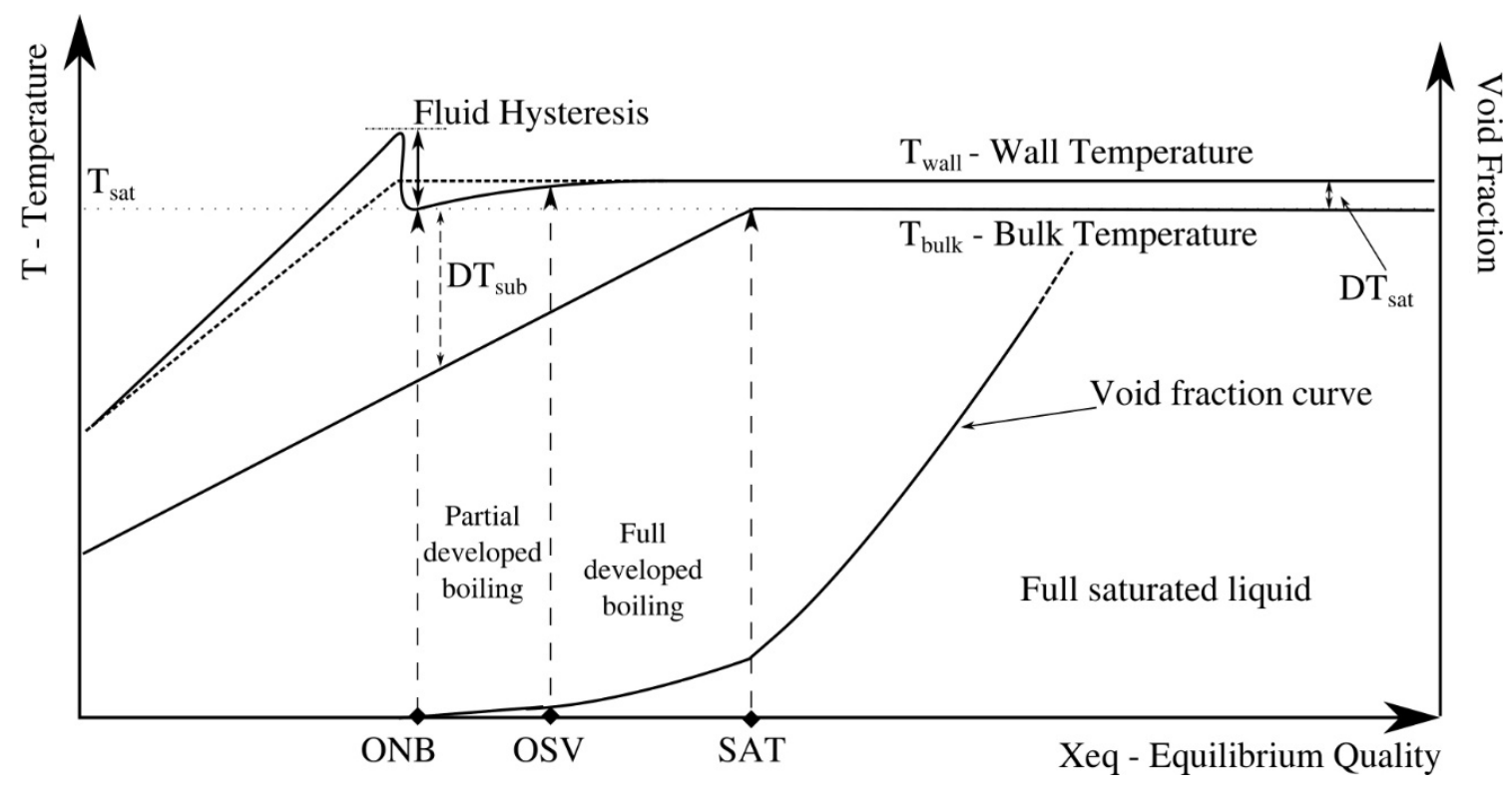

Fig. 5 - Wall temperature, bulk temperature and void fraction trends at the increasing of equilibrium quality

The Onset of Nucleate Boiling (ONB) can be identified by an energy balance, as stated in [28]:

$$
Z_{O N B}=\frac{G c_{p l} D}{4} \cdot\left[\frac{\left(\left(T_{s a t}-T_{l, i n}\right)+\left(\Delta T_{s a t}\right)_{O N B}\right)}{Q}-\frac{1}{h_{l, c o n v}}\right]
$$

The convective heat transfer coefficient $h_{1, \text { conv }}$ can be calculated by the well-known PetukhovGnielinski correlation, where the fluid properties are evaluated at the film temperature:

$$
\frac{\left(T_{l}\left(z_{O N B}\right)+T_{\text {wall }}\left(z_{O N B}\right)\right)}{2}
$$

The only exception is the liquid heat capacity, that is calculated at the average temperature between the inlet and the ONB:

$$
\frac{\left(T_{l}\left(z_{O N B}\right)+T_{l, i n}\right)}{2}
$$

The wall superheating $\left(\Delta T_{\text {sat }}=T_{w}-T_{\text {sat }}\right)$ at the ONB point can be calculated by a modified Frost and Dzakowic [31] correlation for water:

$$
\left(\Delta T_{s a t}\right)_{O N B}=\left(\frac{8 \sigma Q T_{s a t}}{k_{l, s a t} H_{l v, s a t} \rho_{g}}\right)^{0.5} P r_{l}^{0.95}
$$


190

191

192

193

194

196

197

198

199

200

201

202

203

The $\operatorname{Pr}$ number exponent has been changed in this work from 1 to 0.95 , to better agree with the available experimental results. All the proprieties in Eq. (8) are calculated at the saturation temperature $T_{\text {sat. }}$ Tab. 4 shows the equivalent applicability range for FC-72 using similarity criterion, as described in Eqs. (1) to (4):

Tab. 4 - Frost and Dzakowic correlation [31]: applicability range for FC-72

\begin{tabular}{|c|c|c|c|}
\hline Parameters & Water & FC-72 & BO.E.MI.A. data \\
\hline Pressures & $0.1-20 \mathrm{MPa}$ & $0.0075-1.57 \mathrm{MPa}$ & $0.3-0.5 \mathrm{MPa}$ \\
\hline Mass velocity & No restriction & No restriction & $415-1439 \mathrm{~kg} / \mathrm{m}^{2} \mathrm{~s}$ \\
\hline Heat flux & $150 \mathrm{~kW} / \mathrm{m}^{2}$ & $6.5 \mathrm{~kW} / \mathrm{m}^{2}$ & $1.5-181 \mathrm{~kW} / \mathrm{m}^{2}$ \\
\hline
\end{tabular}

The liquid temperature at the ONB point, to be used in the fluid proprieties calculation by Eqs. (6) and (7), is calculated iteratively from the energy balance, as in Eq. (9):

$$
T(x)=T_{i n}+4 \frac{Q \cdot Z_{O N B}}{G \cdot c_{p l} \cdot D}
$$

The heat capacity $C_{p l}$ is calculated at the average temperature between $T_{\text {in }}$ and $T(x)$ where $x$ is $Z_{\text {ONB. }}$

The Onset of Significant Void point is identified through the Saha and Zuber correlation [32], as suggested in the Delhaye et al. model [28]. It is calculated starting from the ONB point. The liquid bulk temperature at the OSV is:

$$
T_{l, O S V}=\Delta T_{O S V}-T_{\text {sat }}
$$

where $\Delta T_{\text {OSV }}$ is the subcooling degree and it is calculated according to the Saha and Zuber [32] criteria to determine the bubble departure point:

$$
\begin{aligned}
& \text { - } P e<700000 ; \quad \Delta T_{O S V}=0.0022 \cdot \frac{Q D}{k_{l}} \\
& \text { - } \quad P e>700000 ; \quad \Delta T_{O S V}=153.8 \cdot \frac{Q}{G \cdot c_{p, l}}
\end{aligned}
$$

where:

$$
P e=\frac{G c_{p . l} \cdot D}{k_{l}}
$$

The fluid properties are calculated at the OSV temperature. From the thermal balance at the OSV point, it is possible to identify the axial position $\left(Z_{\text {osv }}\right)$ where OSV starts:

$$
Z_{\text {OSV }}=Z_{O N B}+\left[H_{l}\left(T_{l, O S V}\right)-H_{l}\left(T_{l, O N B}\right)\right] \cdot \frac{G D}{4 Q}
$$


International Journal of Heat and Mass Transfer 115 (2017) 1074-1090

http://dx.doi.org/10.1016/j.ijheatmasstransfer.2017.07.126

213 ONB and OSV points will be used as boundaries in the void fraction calculations for the partial and 214 fully developed boiling regions.

215

216

217

\section{VOID FRACTION CALCULATION}

Two-phase pressure drop calculation needs the evaluation of the void fraction. The Zuber and Findlay drift flux model [33] is widely used in the literature to evaluate the void fraction $\alpha$ :

$$
\alpha=\frac{\Gamma_{v}}{C_{0} \Gamma+V_{g}}
$$

where $C_{0}$ is the distribution parameter, that is a function of the local vapor void fraction and the local mixture velocity; $V_{g}$ is the weighted drift velocity, that physically depends on the radial profile of the void fraction and can be calculated as a function of local the vapor void fraction and the local vapor velocity; $\Gamma$ is the volumetric flow rate. These parameters, in the original work, are semi-empirical and based on a fluid database. Lahey and Moody [34] proposed different methods to calculate the void fraction in subcooled boiling, based on the Zuber and Findlay [33] model, that was developed to estimate the void fraction in the fully developed boiling region.

$$
\alpha=\frac{x_{v} \cdot \rho_{l} \cdot G}{C_{0}\left(x_{v} \cdot \rho_{l}+\left(1-x_{v}\right) \cdot \rho_{v}\right) G+V_{g} \cdot \rho_{l} \cdot \rho_{v}}
$$

The differences of the Lahey and Moody [36] model from the original one are: (a) the relation between actual vapor quality and equilibrium quality, (b) the distribution parameter $C_{0}$ calculation and (c) the weighted drift velocity $V_{g}$ calculation. Most of the available models calculate the void fraction in fully developed boiling region assuming a zero quality in the partially developed boiling region. However, Levy [35] and Griffith et al. [36] proposed correlations for the void fraction at the OSV. Delhaye et al. [28] improved the Lahey and Moody [34] extending the range up to the end of subcooled region, concatenating different approaches to different regions of subcooled boiling.

(a) Relation between non-equilibrium and equilibrium vapor quality in the subcooled region

The vapor quality $x_{v}$ is the vapor mass fraction in a mixture. It is different but related with the equilibrium quality $x e q$ :

$$
x_{e q}(z)=\frac{H(Z)-H_{l, s a t}}{H_{l v}}
$$

The original model from Lahey and Moody [34] assumes the quality between ONB and OSV (PDB region) equal to zero. However, this approach would lead to an overestimation of the void fraction between the OSV and the saturation point (FDB zone). Therefore, a modified non-equilibrium quality 

model which adopts an approximation of the subcooled void in PDB and FD regions should be used. Delhaye et al. [28] proposed a hyperbolic tangent to approximate the transition.

$$
\begin{gathered}
x_{v}(Z)=0.01 \xi\left\{x_{e q}(Z)-x_{e q}\left(Z_{O N B}\right)\left[\tanh \left(\left(\frac{x_{e q(Z)}}{x_{e q}\left(Z_{O N B}\right)}\right)-1\right)+1\right]\right\} \\
x_{v}(Z)=x_{e q}(Z) \text { if } x_{e q}(Z) \geq x_{v}(Z)
\end{gathered}
$$

$\xi$ is a custom constant that must be identified to allow the first order continuity of the quality function between the PDB and FDB regions at the OSV point, identified by Eq. (13), where the vapor quality at OSV is expressed by the formula:

$$
x_{v, O S V}=\frac{1}{\left(\left(\frac{\rho_{l}}{\rho_{v}}\right) \cdot\left(\frac{1-\alpha_{O S V}}{\alpha_{O S V}}\right)+1\right) \alpha_{O S V}}
$$

where $\alpha_{O S V}$ is the void fraction at OSV originally calculated by Griffith et al. [36] for water. Tab. 5

\begin{tabular}{|c|c|c|c|}
\hline Parameter & Water & $F C-72$ & BO.E.MI.A. data \\
\hline Pressure & $3.4-6.9-10.3 \mathrm{MPa}$ & $0.25-0.57-0.8 \mathrm{MPa}$ & $0.3-0.5 \mathrm{MPa}$ \\
\hline Mass velocity & $80-400 \mathrm{~kg} / \mathrm{m}^{2} \mathrm{~s}$ & $155-1500 \mathrm{~kg} / \mathrm{m}^{2} \mathrm{~s}$ & $415-1439 \mathrm{~kg} / \mathrm{m}^{2} \mathrm{~s}$ \\
\hline Heat flux & $1600-8500 \mathrm{~kW} / \mathrm{m}^{2}$ & $80-365 \mathrm{~kW} / \mathrm{m}^{2}$ & $1.5-181 \mathrm{~kW} / \mathrm{m}^{2}$ \\
\hline
\end{tabular}
summarizes the applicability range for the original Griffith et al. [36] model.

Tab. 5 - Griffith [36] OSV model applicability range

To extend the applicability to other fluids Delhaye et al. [28] changed that model, introducing the capillarity length:

$$
\alpha_{O S V}=\frac{4 a}{D}
$$

where:

$$
a=7.5 \frac{Q k_{l} P r_{l}}{h_{l}^{2}\left[T_{s a t}-T_{l}\left(z_{O S V}\right)\right]} \frac{L_{c a p}}{D}
$$

The capillary length $L_{c a p}$ is defined as:

The single-phase heat transfer coefficient $h_{l}$ is evaluated by the Dittus-Boelter correlation and all the fluid properties are calculated by Eq. (9) at the OSV temperature. 
263

(b) Distribution parameter

The distribution parameter $C_{0}$ used in Eq. (15) is calculated by the equation from Nabizadeh et al. [37]:

$$
C_{0}=\left(1+\frac{1-x_{v}}{x_{v}} \cdot \frac{\rho_{v}}{\rho_{l}}\right)^{-1} \cdot\left(1+\frac{1}{n} \cdot F r^{-0.1} \cdot\left(\frac{\rho_{v}}{\rho_{l}}\right)^{n} \cdot\left(\frac{1-x_{v}}{x_{v}}\right)^{\frac{11 * n}{9}}\right)
$$

where:

$$
n=\sqrt{0.6 \frac{\rho_{l}-\rho_{v}}{\rho_{l}}}
$$

$\mathrm{Fr}$ is the Froude number defined as:

$$
F r=\frac{G^{2}}{g \cdot D \cdot \rho_{l}^{2}}
$$

The void fraction $\alpha$ is largely influenced by the distribution parameter; Delhaye et al. [28] defines Eq. (22) as the most promising in the literature, because it involves pressure, mass flux and quality. Other equations, as from Saha and Zuber [32], use a constant value and Dix [38] uses a function of quality. Also in [28] a new correlation was proposed, but it is specific for their facility and not suitable for FC-72.

\section{(c) Weighted drift velocity}

Eq. (14) is weakly influenced by the weighted drift velocity and the original formula proposed by Zuber and Findlay [33] is accurate enough for the calculation, as stated in [28]:

$$
V_{g}=1.41\left(\frac{\sigma \cdot g\left(\rho_{l}-\rho_{v}\right)}{\rho_{l}^{2}}\right)^{0.25}
$$

\section{PRESSURE DROPS IN FLOW BOILING}

Some examples of pressure drop trends at different heat fluxes, from the BO.E.MI.A. experiments, are shown in Fig. 6. The same trends were also observed from other authors, as in Kim and Mudawar [39].

The pressure drop increment is not constant and four different zones can be identified (Fig. 7). 

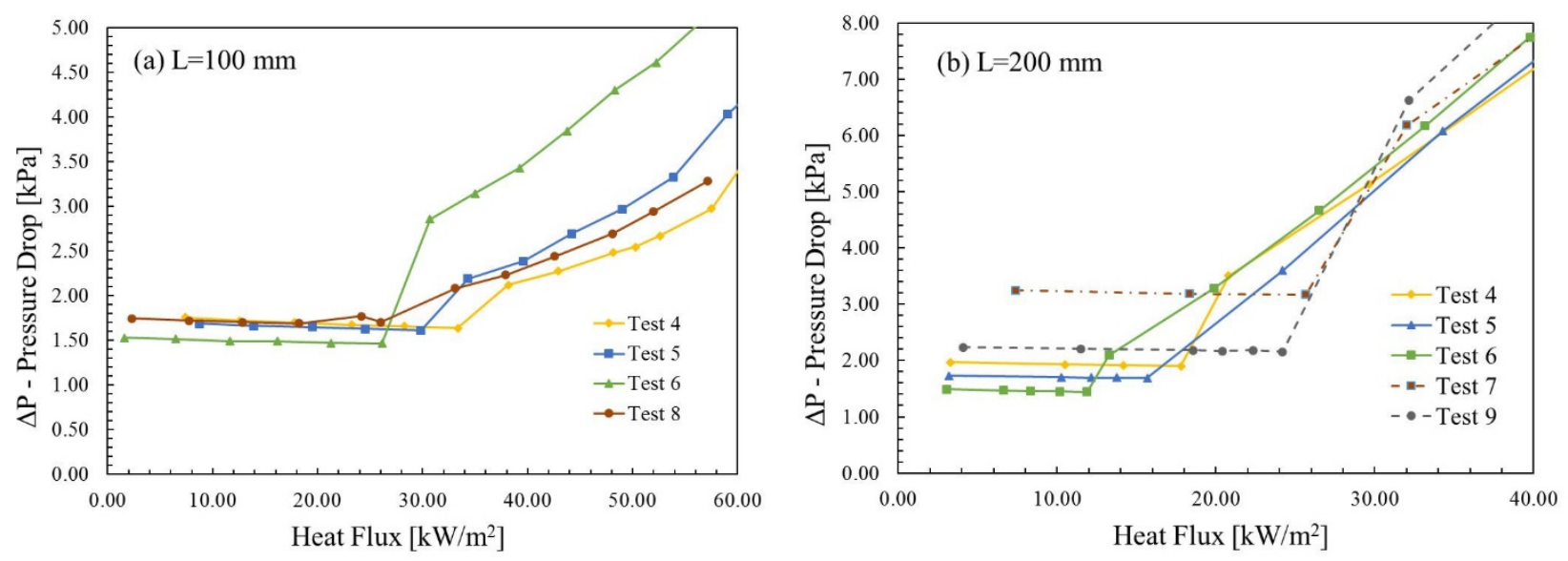

Fig. 6 - Total pressure drops at different heat fluxes, for 100mm (a) and $200 \mathrm{~mm}$ (b) tubes.

The subcooled fluid enters the channel (1) and the pressure drops are related only to the liquid frictional losses $(d p / d z)_{f}$. When the fluid reaches the subcooled boiling point at ONB the bubbles that are formed on the tube reduce the available spaces in the channel accelerating the fluid and consequently pressure drop increases (2). However, the embryo bubbles at ONB are formed in cavities and when they emerge encounter a large temperature gradient causing bubble reduction or implosion, with the resulting instabilities. The instabilities related to the wall superheating hysteresis are particularly marked for wetting fluids as fluorocarbons (You et al. [1]). In the full developed boiling region (3), before the saturation point, the acceleration pressure drop $(d p / d z)_{a c c}$ quickly increases with the void fraction. The frictional losses are higher due to the presence of two phases flowing through the tube. In region (2) and (3), the single-phase model fails to predict pressure drops and it is necessary to adopt a new model. The void fraction, thanks to its relation to the acceleration and frictional pressure drops, can be used as the main parameter to adapt usual two-phase models, such as Lockhart-Martinelli [15], Friedel [12], and others. The choice of using two-phase models in the subcooled region instead of developing specific correlations is the wide validity range of the model and the possibility of use only one model for all the boiling zones. Margulis and Shwageraus [40] followed the same approach in their work, using the Osmachkin and Borisov [41] correlation. After the saturated point, the pressure drops are well known (4) and the traditional two-phase models can be used.

The total pressure drop is expressed as:

$$
-\left(\frac{d p}{d z}\right)_{t}=-\left(\frac{d p}{d z}\right)_{f}-\left(\frac{d p}{d z}\right)_{a c c}-\left(\frac{d p}{d z}\right)_{g}
$$

In the single-phase zone, only the friction contribution is considered. 
The acceleration contribution, also considered in the subcooled region, is here expressed in terms of the vapor quality $x_{v}$ instead of the equilibrium quality $x_{e q}$, as in Eq. (27):

$$
-\left(\frac{d p}{d z}\right)_{a c c}=\frac{G^{2}}{\rho_{l}}\left(\frac{\rho_{l}}{\rho_{v}} \frac{x_{v}^{2}}{\alpha}+\left(\frac{\left(1-x_{v}\right)^{2}}{(1-\alpha)}-1\right)\right)
$$

Fig. 7 shows the emphasized theoretical trends; the gravitational pressure drop $(d p / d z)_{g}$ is null because the channel is horizontal.

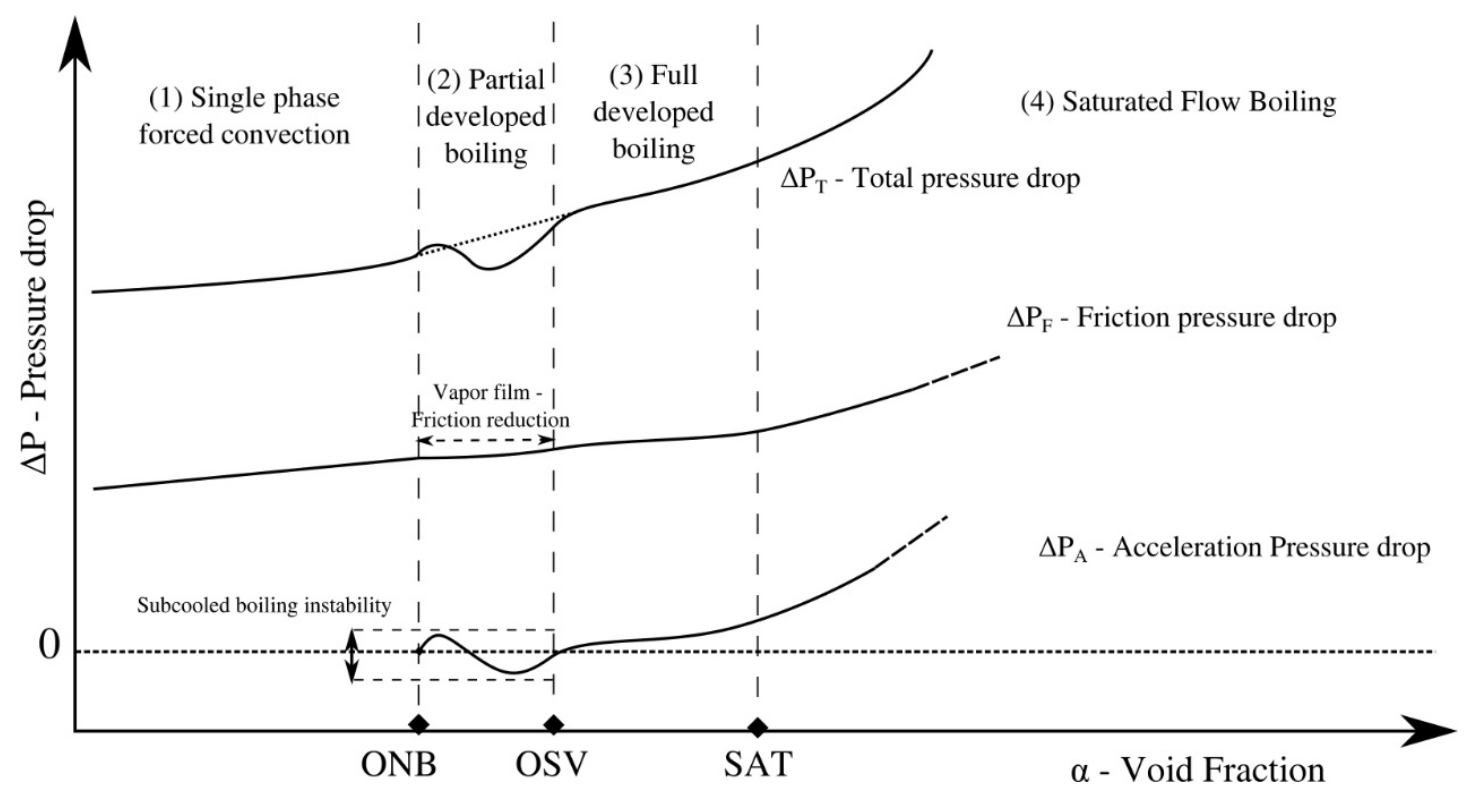

Fig. 7 - Pressure drop contributions at different void fractions

\subsection{Pressure drops in single phase transition flow}

In the analyzed tests, the fluid is subcooled at the inlet and a zone of the tube is in single-phase forced convection until the onset of nucleate boiling occurs. As described, the Reynolds number in the ENEA experiments varied from 2750 to 4500 . Being these values between the conservative range $2000<\operatorname{Re}$ $<4000$, the flow is mainly in transition between the laminar and turbulent flow. In this region, there are no reliable models able to describe the phenomenon. Several empirical equations have been proposed for computing the transitional pressure drop: Brownlie [42]; Cheng and Chiew [43]; Ligrani and Moffat [44]; Yalin and Da Silva [45]. However, as shown in [46], a simple interpolation method may work better in calculating pressure drop in the transition range.

In a first approximation, the pressure drop must vary between the boundaries of laminar and turbulent flow. Thus, if the channel is long enough, it is possible to consider the average pressure drop in a section of the channel, neglecting the physical oscillation between laminar and turbulent flows. In fact, in the same section and over a short time interval, the fluid statistically changes its behavior 
cyclically. Then, the friction factor variations can be related to the Reynolds number by a polynomial interpolation between the laminar and turbulent friction factor. To avoid any discontinuity in the functions at the boundaries, a third order polynomial has been adopted. This polynomial function can be expressed as:

$$
f_{\text {tran }}=\alpha \cdot R e^{3}+\beta \cdot R e^{2}+\gamma \cdot R e+\delta
$$

The 4 constants $\alpha, \beta, \gamma, \delta$ can be obtained by a 4 -equations system, where the following boundary conditions are imposed:

$$
\left\{\begin{array}{cc}
A: f_{\text {lam }}=f_{\text {tran }} & \text { For } R e=1100 \\
B: f_{\text {r,trans }}=f_{\text {turb }} & \text { For Re }=8000 \\
C: f_{\text {lam }}{ }^{\prime}=f_{\text {tran }}{ }^{\prime} & \text { For } R e=2000 \\
D: f_{\text {tran }}{ }^{\prime}=f_{\text {turb }}{ }^{\prime} & \text { For } R e=4000
\end{array}\right.
$$

The first two conditions are taken far from the boundaries, when the fluid is certainly laminar or turbulent; the second two conditions are needed to assure the function continuities at the boundaries. The two well know equations used for laminar and turbulent pressure drops in single phase are:

$$
\text { Darcy friction factor } \quad f_{\text {lam }}=\frac{64}{R e}
$$

$$
\text { Colebrook friction factor } \quad 1 / \sqrt{f_{\text {turb }}}=-2 \log \left(\frac{\varepsilon}{3.7 D}+\frac{2.51}{R e \sqrt{f_{\text {turb }}}}\right)
$$

The Colebrook equation (31) [47] is solved recursively. $\varepsilon$ is absolute roughness of the wall, $D$ is the channel diameter, and $R e$ is the Reynolds number. Fig. 8 represents schematically the friction factor trend.

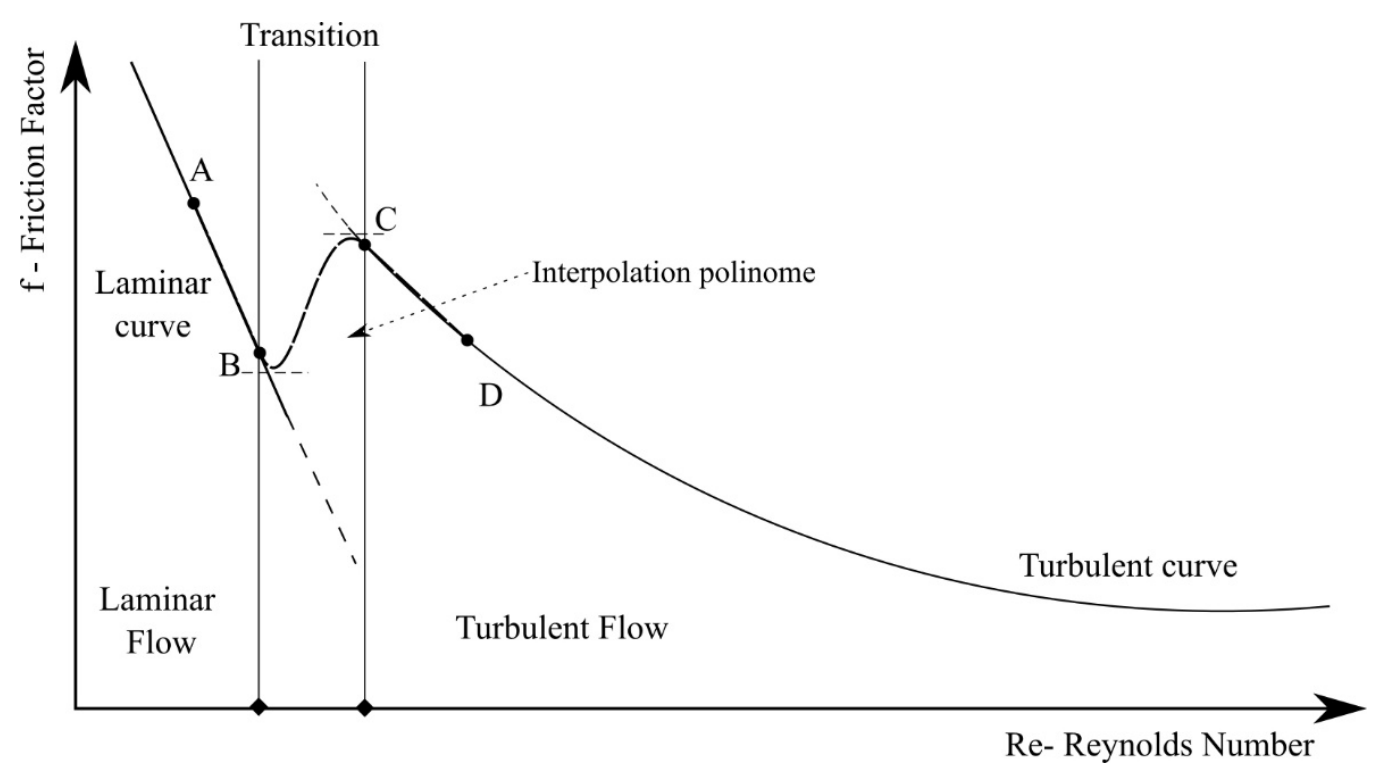

Fig. 8 - Interpolation curve for the transition friction factor; A, B, C, D are the 4 boundary condition points. 
International Journal of Heat and Mass Transfer 115 (2017) 1074-1090

http://dx.doi.org/10.1016/j.ijheatmasstransfer.2017.07.126

348 Then, the frictional pressure drop in the subcooled liquid from inlet up to the ONB can be calculated 349 by the equation:

$$
\Delta P_{f}=f \frac{z_{O N B}}{D} \frac{G^{2}}{2 \rho_{l}}
$$

351

Tab. 6 Applicability Criteria for Owens and Schrock's [50] and Tong et al. [51] correlations.

Owens and Schrock [50]

\begin{tabular}{r|lll}
\hline Pressure & $0.34-2.76 \mathrm{MPa}$ & $0.02-0.20 \mathrm{MPa}$ & $0.3-0.5 \mathrm{MPa}$ \\
Mass velocity & $1143-5322 \mathrm{~kg} / \mathrm{m}^{2} \mathrm{~s}$ & $745-3370 \mathrm{~kg} / \mathrm{m}^{2} \mathrm{~s}$ & $415-1439 \mathrm{~kg} / \mathrm{m}^{2} \mathrm{~s}$ \\
Heat flux & $675-4000 \mathrm{~kW} / \mathrm{m}^{2}$ & $20-108 \mathrm{~kW} / \mathrm{m}^{2}$ & $1.5-181 \mathrm{~kW} / \mathrm{m}^{2}$ \\
& & & \\
Tong et al. [51] & & $0.03-0.11 \mathrm{MPa}$ & $0.3-0.5 \mathrm{MPa}$ \\
\hline Pressure & $0.4-1.6 \mathrm{MPa}$ & $16220-28685 \mathrm{~kg} / \mathrm{m}^{2} \mathrm{~s}$ & $415-1439 \mathrm{~kg} / \mathrm{m}^{2} \mathrm{~s}$ \\
Mass velocity & $25000-45000 \mathrm{~kg} / \mathrm{m}^{2} \mathrm{~s}$ & $0-217.5 \mathrm{~kW} / \mathrm{m}^{2}$ & $1.5-181 \mathrm{~kW} / \mathrm{m}^{2}$
\end{tabular}


The ranges of applicability of the Owens and Schrock correlation are closer than those of Tong correlation to the BO.E.MI.A. database.

The experimental data are related to the total pressure drops from the inlet to the outlet and the fluid enters in the tube in liquid single phase with a high degree of subcooling. The pressure drop data where the fluid reaches saturation (54 points) are not considered in the assessment of subcooled boiling method, but only in assessing the whole methodology. The experimental setup is provided with the pressure transducer at inlet and outlet, thus only the total pressure drop, from inlet to outlet, was available for the assessment.

The proposed methodology uses a different correlation to calculate pressure drops for each region. In single phase Eq (32) was used; for subcooled and saturated flow boiling zones the correlations summarized in Tab. 7 were used, with the void fraction and quality obtained from Eqs. 15 and 17, respectively. However, it should be noted that the subcooled and saturated boiling correlation cannot be the same in the two zones. In fact, the best agreement was obtained using different correlations to best fit the data. For comparison purposes, two subcooled boiling correlations (Owens-Schrock [50], and Tong [51]) are reported in Table 8 and all the correlations are assessed in Tables 9-11.

Tab. 7 - Two-phase pressure drop models

\begin{tabular}{|c|c|}
\hline Author(s) & Equations \\
\hline $\begin{array}{l}\text { Lockhart-Martinelli [15] } \\
(1.49<D<25.4 \mathrm{~mm})\end{array}$ & 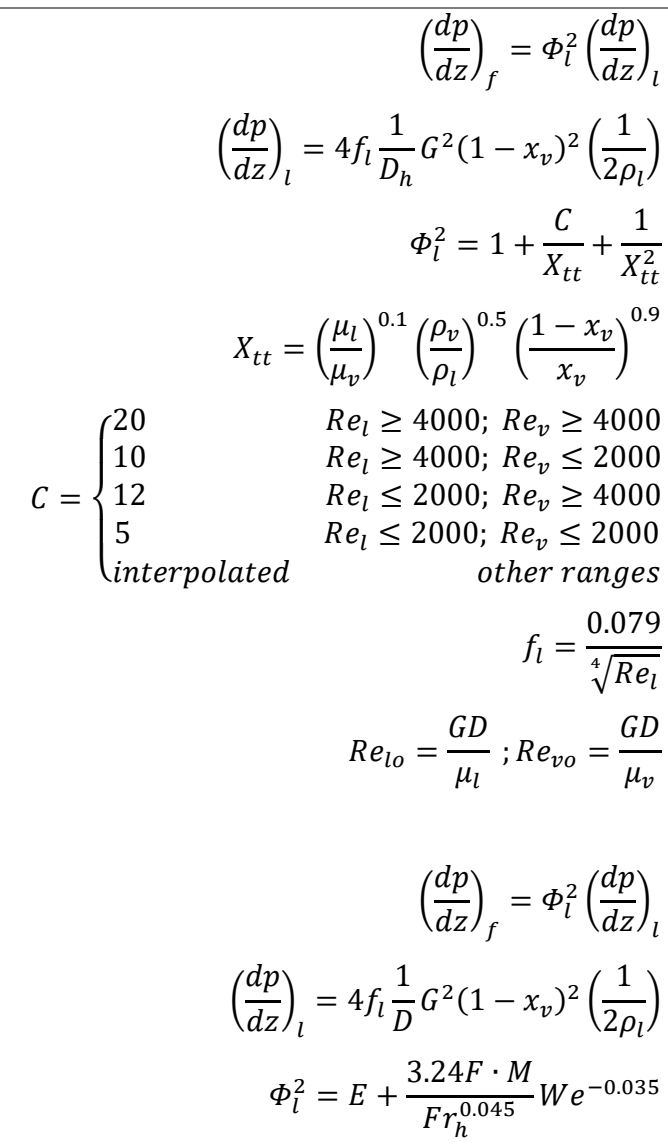 \\
\hline
\end{tabular}


International Journal of Heat and Mass Transfer 115 (2017) 1074-1090

http://dx.doi.org/10.1016/j.ijheatmasstransfer.2017.07.126

$$
\begin{array}{r}
f_{l}=\frac{0.079}{\sqrt[4]{R e_{l}}} ; \quad f_{v}=\frac{0.079}{\sqrt[4]{R e_{v}}} \\
F r=\frac{G^{2}}{\rho_{l}^{2} \cdot g \cdot D} \\
W e_{l o}=\frac{G^{2} D}{\rho_{l} \sigma} \\
E=\left(1-x_{v}\right)^{2}+x_{v}^{2} \frac{\rho_{l}}{\rho_{v}} \frac{f_{v}}{f_{l}} \\
F=x_{v}^{0.78}\left(1-x_{v}\right)^{0.224} \\
M=\left(\frac{\rho_{l}}{\rho_{v}}\right)^{0.91} *\left(\frac{\mu_{v}}{\mu_{l}}\right)^{0.19}\left(1-\frac{\mu_{v}}{\mu_{l}}\right)^{0.7}
\end{array}
$$

Chawla [48]

$(6<D<154 \mathrm{~mm})$

Chisholm [14]

$(1.49<D<25.4 \mathrm{~mm})$

$$
\left(\frac{d p}{d z}\right)_{f}=\Phi_{l}\left(\frac{d p}{d z}\right)_{l}
$$

$$
\begin{gathered}
\left(\frac{d p}{d z}\right)_{l}=4 f_{l} \frac{1}{D} G^{2}\left(1-x_{v}\right)^{2}\left(\frac{1}{2 \rho_{l}}\right) \\
\Phi_{l}=x^{1.75}\left(1+S \frac{\left(1-x_{v}\right)}{x_{v}} \frac{\rho_{v}}{\rho_{l}}\right)^{2.375}
\end{gathered}
$$$$
\frac{1}{S}=9.1 \frac{1-x_{v}}{x_{v}}\left(R e_{v} F r\right)^{-0.167}\left(\frac{\rho_{l}}{\rho_{v}}\right)^{-0.9}\left(\frac{\mu_{l}}{\mu_{v}}\right)^{0.5}
$$$$
F r=\frac{G^{2}}{\rho_{l}^{2} \cdot g \cdot D}
$$

$$
\begin{array}{r}
\left(\frac{d p}{d z}\right)_{f}=\Phi_{l}^{2}\left(\frac{d p}{d z}\right)_{l} \\
\left(\frac{d p}{d z}\right)_{l}=4 f_{l} \frac{1}{D} G^{2}\left(\frac{1}{2 \rho_{l}}\right) \\
f_{l, v}= \begin{cases}\frac{0.079}{\sqrt[4]{R e_{l, v}}} & R e_{l, v} \geq 2000 \\
\frac{16}{R e_{l, v}} & R e_{l, v}<2000\end{cases}
\end{array}
$$

$\Phi_{l}^{2}=1+\left(Y^{2}-1\right) B x_{v}^{\frac{2-n}{2}}\left(1-x_{v}\right)^{\frac{2-n}{2}}+x_{v}^{2-n}$ where $n=0.25$ (Blasius)

$$
\begin{aligned}
& Y=\left(\frac{Y_{b}}{Y_{a}}\right)^{1 / 2} \\
& Y_{a}=f_{l} \frac{2 G^{2}}{D \rho_{l}} ; Y_{b}=f_{v} \frac{2 G^{2}}{D \rho_{v}} \\
& \left(\begin{array}{l}
\frac{55}{\sqrt{G}} \\
2400
\end{array} \quad 0 \leq Y<9.5 ; G \geq 1900\right. \\
& 0 \leq Y<9.5 ; 500 \leq G<1900 \\
& 0 \leq Y<9.5 ; G<500 \\
& 9.5 \leq Y<28 ; G \leq 600 \quad \text { G in } \frac{\mathrm{kg}}{\mathrm{m}^{2}} s \\
& 9.5 \leq Y<28 ; G>600 \\
& Y \geq 28
\end{aligned}
$$


http://dx.doi.org/10.1016/j.ijheatmasstransfer.2017.07.126

Müller-Steinhagen

and Heck [49]

(D $>4 \mathrm{~mm})$

$$
\begin{array}{r}
\left(\frac{d p}{d z}\right)_{f}=G\left(1-x_{v}\right)^{\frac{1}{3}}+B x_{v}^{3} \\
G=A+2(B-A) x_{v} \\
A=\left(\frac{d p}{d z}\right)_{l}=4 f_{l} \frac{1}{D} G^{2}\left(\frac{1}{2 \rho_{l}}\right) \\
B=\left(\frac{d p}{d z}\right)_{l}=4 f_{v} \frac{1}{D} G^{2}\left(\frac{1}{2 \rho_{v}}\right) \\
f_{l, v}= \begin{cases}\frac{0.079}{\sqrt[4]{R e_{l, v}}} & R e_{l, v} \geq 2000 \\
\frac{16}{R e_{l, v}} & R e_{l, v}<2000\end{cases}
\end{array}
$$

Tab. 8 - Two-phase pressure drop models for subcooled boiling

\section{Name}

Equations

Owens-Schrock [50]

$(3<D<4.6 \mathrm{~mm})$

$$
\frac{\left(\frac{d p}{d z}\right)_{s u b}}{\left(\frac{d p}{d z}\right)_{a d}}=\left(0.97+0.028 e^{6.13 \frac{z_{s u b}}{L_{s a t}}}\right)
$$

Tong [51]

$(1.05<D<2.44 \mathrm{~mm})$

$$
\frac{\left(\frac{d p}{d z}\right)_{s u b}}{\left(\frac{d p}{d z}\right)_{a d}}=\left\{\begin{array}{lll}
\left(\frac{Z_{\text {sub }}}{L_{s a t}}\right)^{1.3} & e^{\frac{Z_{s u b}}{L_{s a t}}+0.4} & \frac{L}{D}=50 \\
\left(\frac{Z_{\text {sub }}}{L_{\text {sat }}}\right)^{1.3} & e^{\frac{Z_{s u b}}{L_{\text {sat }}}+1.35} & \frac{L}{D}=25
\end{array}\right.
$$

The proposed methodology provides encouraging results by using Friedel [12] and Chisholm [14] correlations in the subcooled boiling zones. A low agreement has been obtained with the Chawla [48], Lockhart-Martinelli [15] and Müller-Steinhagen and Heck [49] correlations. The other two subcooled boiling correlations have been also considered (on the right side of the following Tables 9 to 11) to compare the results from the present methodology with authoritative and recognized correlations.

\section{METHODOLOGY ASSESSMENT}

The methodology has been applied to the ENEA database from the BO.E.MI.A. test section. The

Mean Percentage Error (MPE, Eq. (33)), the Mean Absolute Percentage Error (MAPE, Eq. (34)) and mean percentage error (MPE) is the computed average of percentage errors by which forecasts of a model differ from actual values of the quantity being forecast.

$$
M P E=\frac{100 \%}{N} \sum_{i=1}^{n} \frac{A-C}{A}
$$


401

402

403

404

405

406

407

408

409

410

411

412

413

414

$A$ is the actual measured value of the quantity being predicted, $C$ is the calculated value and $N$ is the number of measured values. The formula is useful to understand how far the mean prediction is from the data and it has the advantage of neglecting any white noise due to the instrumentation.

The Mean Absolute Percentage Error is:

$$
M A P E=\frac{100 \%}{N} \sum_{i=1}^{n} \frac{|A-C|}{A}
$$

MAPE is a quantity used to measure how close predictions are to the eventual outcomes and represents the mean error committed for a single forecast.

\subsection{Single-phase transient flow assessment}

Assessing Eq 32 for the pressure drop in transitional regime a good agreement was obtained: 100\% of the predicted data (79 points) have an error $<30 \%$, the MAPE is $4.71 \%$ and the MPE $0.79 \%$.

However, the pressure drop values are quite close to the differential pressure instrument error, \pm 510 $\mathrm{Pa}$, both in 100 and $200 \mathrm{~mm}$ channels, thus the measurements may be affected by an experimental error that can strongly affect the model uncertainty. A graphical representation of the results is shown in Fig. 9:

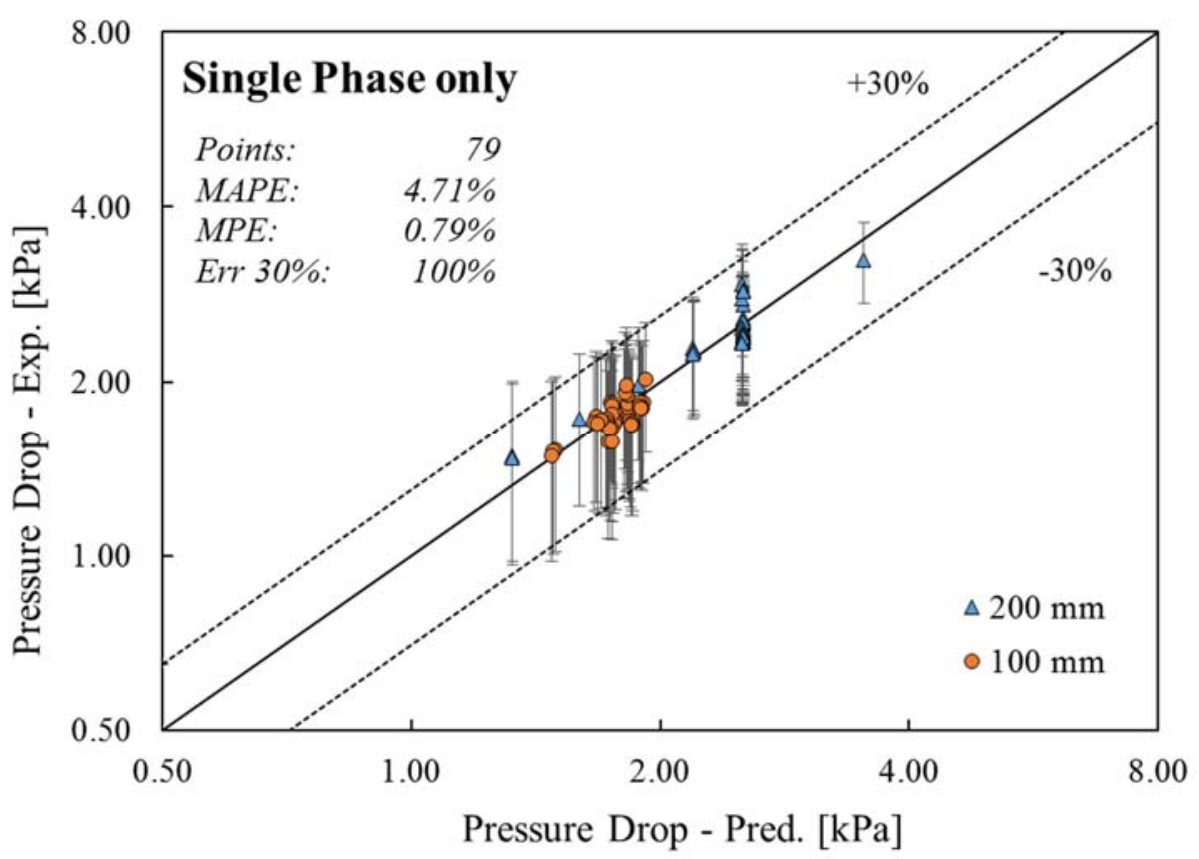

Fig. 9 - Pressure drop, experimental vs predicted in $100 \mathrm{~mm}$ and $200 \mathrm{~mm}$ tubes.

During the experiment, the average measured single-phase pressure drops were about $2.3 \mathrm{kPa}$ for the $200-\mathrm{mm}$ tube and $1.7 \mathrm{kPa}$ for the $100 \mathrm{~mm}$. The maximum and minimum values were respectively 
Comparing the results with the laminar and turbulent equations (30) and (31), the experimental data are respectively $\approx 1 / 3$ of the Eq. ( 30 ) results (laminar) and $\approx 15$ times compared to the turbulent Eq. (31). Thanks to its good agreement, once the void fraction is calculated, it can be used in any of the available pressure drop models before the ONB point. However, it must be noted that the single-phase pressure drops are quite low (few $\mathrm{kPa}$ ), thus the instrumentation error is high if compared with the pressure drops. If all the 139 subcooled points (subcooled boiling only) were considered in single phase, the predicted pressure drop should be lower than the experimental ones, as shown in Fig. 10, therefore the single-phase model is not able to predict the pressure drops in the subcooled flow.

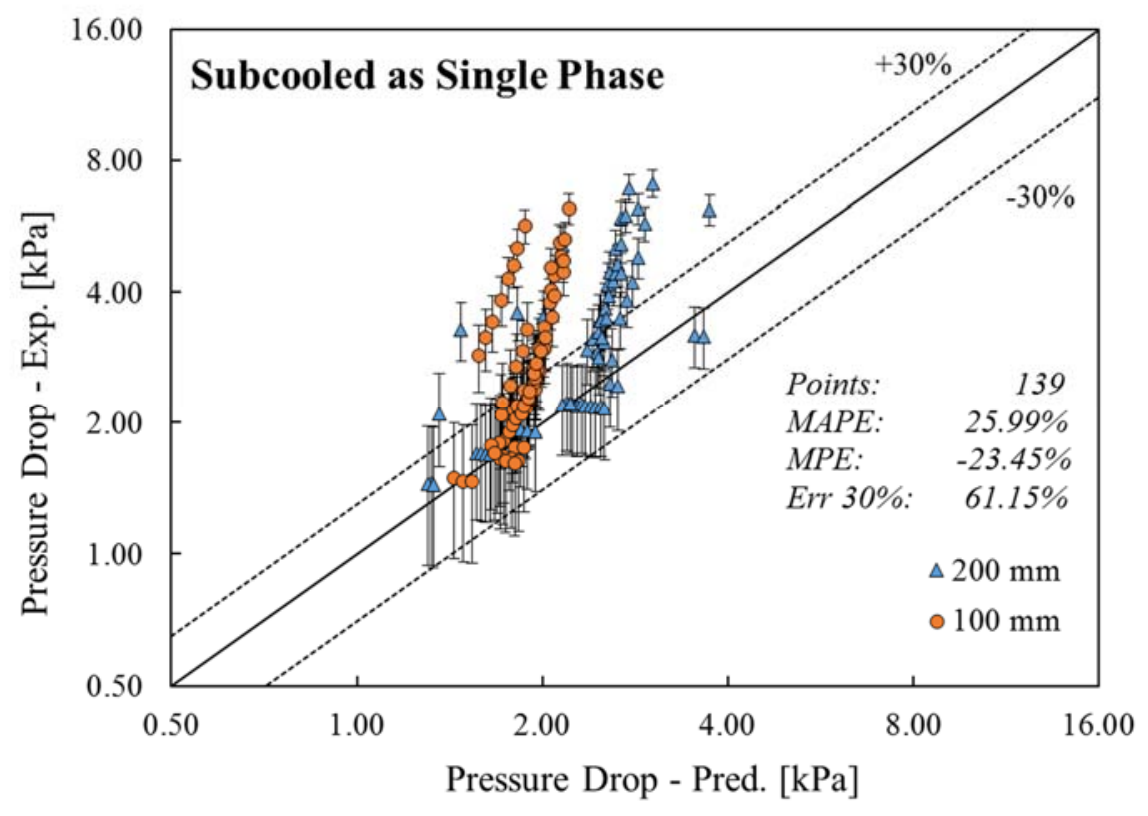

Fig. 10 - Single-Phase pressure drops

\subsection{Subcooled flow boiling assessment}

The assessments for the subcooled flow boiling equations of Tab. 7 are reported in Tab. 9, where all the points are assessed considering the saturated correlations of Müller-Steinhagen and Heck [49], Friedel [12], Lockhart-Martinelli [15], Chisholm [14] and Chawla [48] calculated with the vapour quality and void fraction from Eqs. 15 and 17, and the literature correlations of Owens-Schrock [50] and Tong [51], specifically developed for subcooled flow boiling. The partial results for the total pressure drops in the $100 \mathrm{~mm}$ and the $200 \mathrm{~mm}$ tubes are shown in in Tables 10 and 11, respectively. 
International Journal of Heat and Mass Transfer 115 (2017) 1074-1090

http://dx.doi.org/10.1016/j.ijheatmasstransfer.2017.07.126

Tab. 9 - Results for subcooled flow boiling points with the present methodology- and literature subcooled

\begin{tabular}{|c|c|c|c|c|c|c|c|}
\hline \multicolumn{8}{|c|}{ Global (139 points) } \\
\hline & \multicolumn{5}{|c|}{ Present methodology } & \multicolumn{2}{|c|}{$\begin{array}{c}\text { Subcooled boiling } \\
\text { correlations }\end{array}$} \\
\hline $\begin{array}{c}\text { Subcooled } \\
\text { boiling } \\
\text { model }\end{array}$ & $\begin{array}{c}\text { Chisholm } \\
\text { [14] }\end{array}$ & $\begin{array}{c}\text { Friedel } \\
{[12]}\end{array}$ & $\begin{array}{c}\text { Müller- } \\
\text { Steinhagen } \\
\text { and Heck } \\
{[49]}\end{array}$ & $\begin{array}{c}\text { Lockhart- } \\
\text { Martinelli } \\
{[15]}\end{array}$ & $\begin{array}{c}\text { Chawla } \\
{[48]}\end{array}$ & $\begin{array}{c}\text { Owens- } \\
\text { Schrock [50] }\end{array}$ & Tong [51] \\
\hline MPE & $-2.83 \%$ & $13.48 \%$ & $22.41 \%$ & $-32.25 \%$ & $51.30 \%$ & $-13.78 \%$ & $26.09 \%$ \\
\hline MAPE & $21.57 \%$ & $19.02 \%$ & $24.12 \%$ & $40.35 \%$ & $51.32 \%$ & $32.78 \%$ & $29.05 \%$ \\
\hline $\pm 30 \%$ & $79.86 \%$ & $76.26 \%$ & $67.63 \%$ & $61.87 \%$ & $15.11 \%$ & $65.47 \%$ & $52.52 \%$ \\
\hline
\end{tabular}

Tab. 10 - 100mm results for subcooled flow foiling points with the present methodology and literature subcooled correlation

\begin{tabular}{|c|c|c|c|c|c|c|c|}
\hline \multicolumn{8}{|c|}{$100 \mathrm{~mm}$ (76 points) } \\
\hline & \multicolumn{5}{|c|}{ Present methodology } & \multicolumn{2}{|c|}{ Subcooled boiling correlations } \\
\hline $\begin{array}{c}\text { Subcooled } \\
\text { boiling } \\
\text { model }\end{array}$ & $\begin{array}{c}\text { Chisholm } \\
\text { [14] }\end{array}$ & $\begin{array}{c}\text { Friedel } \\
{[12]}\end{array}$ & $\begin{array}{c}\text { Müller- } \\
\text { Steinhagen } \\
\text { and Heck } \\
\text { [49] }\end{array}$ & $\begin{array}{c}\text { Lockhart- } \\
\text { Martinelli } \\
{[15]}\end{array}$ & $\begin{array}{c}\text { Chawla } \\
\text { [48] }\end{array}$ & $\begin{array}{c}\text { Owens- } \\
\text { Schrock [50] }\end{array}$ & Tong [51] \\
\hline MPE & $-2.44 \%$ & $14.87 \%$ & $24.44 \%$ & $-33.75 \%$ & $51.38 \%$ & $-10.46 \%$ & $29.89 \%$ \\
\hline MAPE & $20.82 \%$ & $17.45 \%$ & $24.44 \%$ & $40.42 \%$ & $51.38 \%$ & $28.64 \%$ & $29.89 \%$ \\
\hline $\pm 30 \%$ & $78.95 \%$ & $78.95 \%$ & $68.42 \%$ & $60.53 \%$ & $15.79 \%$ & $73.68 \%$ & $52.63 \%$ \\
\hline
\end{tabular}

Tab. 11 - 200mm results for subcooled flow foiling points with the present methodology and literature subcooled correlation

\begin{tabular}{|c|c|c|c|c|c|c|c|}
\hline \multicolumn{8}{|c|}{$200 \mathrm{~mm}$ (63 points) } \\
\hline & \multicolumn{5}{|c|}{ Present methodology } & \multicolumn{2}{|c|}{ Subcooled boiling correlations } \\
\hline $\begin{array}{c}\text { Subcooled } \\
\text { boiling } \\
\text { model }\end{array}$ & $\begin{array}{c}\text { Chisholm } \\
\text { [14] }\end{array}$ & $\begin{array}{c}\text { Friedel } \\
{[12]}\end{array}$ & $\begin{array}{c}\text { Müller- } \\
\text { Steinhagen } \\
\text { and Heck } \\
\text { [49] }\end{array}$ & $\begin{array}{c}\text { Lockhart- } \\
\text { Martinelli } \\
{[15]}\end{array}$ & $\begin{array}{c}\text { Chawla } \\
{[48]}\end{array}$ & $\begin{array}{c}\text { Owens- } \\
\text { Schrock [50] }\end{array}$ & Tong [51] \\
\hline MPE & $-3.29 \%$ & $11.81 \%$ & $19.95 \%$ & $-30.44 \%$ & $51.20 \%$ & $-17.79 \%$ & $21.50 \%$ \\
\hline MAPE & $22.47 \%$ & $20.90 \%$ & $23.72 \%$ & $40.27 \%$ & $51.25 \%$ & $37.78 \%$ & $28.03 \%$ \\
\hline $\pm 30 \%$ & $80.95 \%$ & $73.02 \%$ & $66.67 \%$ & $63.49 \%$ & $14.29 \%$ & $55.56 \%$ & $52.38 \%$ \\
\hline
\end{tabular}


450 The subcooled boiling pressure drops trends by using the Owens and Schrock [50] and Tong [51]
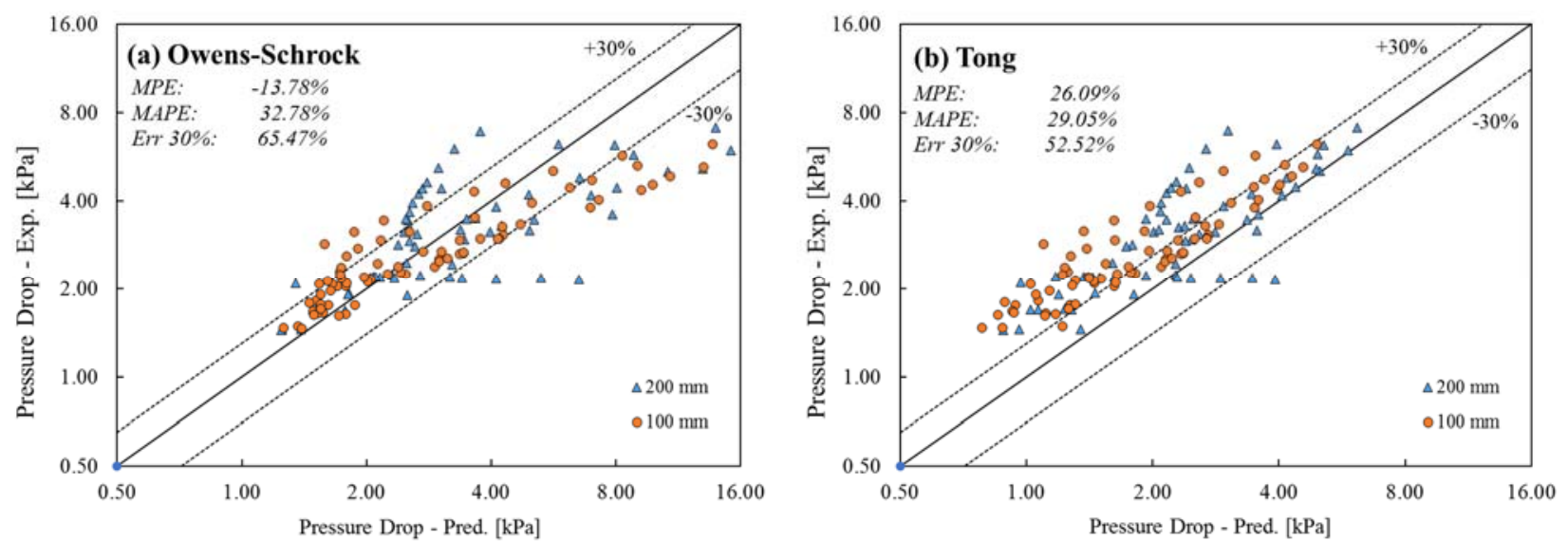
correlations are shown in Fig. 11. The same trends for the proposed methodology, adopting different models, are shown in Fig. 12.

The average experimental error is $\pm 9.5 \%$, ranging between a minimum of $\pm 3 \%$ for high pressure drop values and $\pm 35.4 \%$ for the lower ones.

Fig. 11 - Pressure drop prediction for specific subcooled boiling correlations: (a) Owens-Schrock [50], (b) Tong [51]

From Figures 11, 12 and the results summarized in Tab. 9, it is evident how the analysed experimental data are well predicted when the Chisholm correlation [14] is used. It presents a MAPE of 21.57\% and a MPE of $-2.83 \%$, and it is able to predict $79.86 \%$ of the points with an error lower than $\pm 30 \%$. The best results are for the $100 \mathrm{~mm}$ tube, where the Chisholm correlation [14] obtains a MAPE of $20.82 \%$ and a MPE of $-2.44 \%$ with the $78.95 \%$ of data within $\pm 30 \%$ error. As it is shown in Fig. $11-$ 12 and Tab. 8-9-10 the MAPE alone is not always the best instrument to evaluate the prediction accuracy for a correlation, as it cannot fully describe the quality of a prediction. In fact, any deviation from the mean values is not evident by this statistical instrument, neither the error sign. The lower MAPE is for the Friedel correlation [12], but the trends, the MPE and the $\pm 30 \%$ error bands show a better agreement for Chisholm correlation [14]. The best results obtained from the specific subcooled boiling correlations come from the Owens-Schrock [50] correlation, where the MPE is $-13.78 \%$, MAPE 32.78 and $65.47 \%$ of the data has an error within $\pm 30 \%$. These correlations present a larger error than the ones proposed within the methodology and show a wider dispersion, particularly marked for the $200 \mathrm{~mm}$ data. 
International Journal of Heat and Mass Transfer 115 (2017) 1074-1090

http://dx.doi.org/10.1016/j.ijheatmasstransfer.2017.07.126

472 The present conclusion is in agreement with Friedel [52] and Tribbe and Müller-Steinhagen [53],

473 where the Chisholm [14] correlation was identified as the most suitable one, performing very well in

474 calculating pressure drops for $\mu_{l} / \mu_{g}>1000$ and with mass velocities greater than $100 \mathrm{~kg} / \mathrm{m}^{2} \mathrm{~s}$, as in the 475 BO.E.MI.A. setup.

476
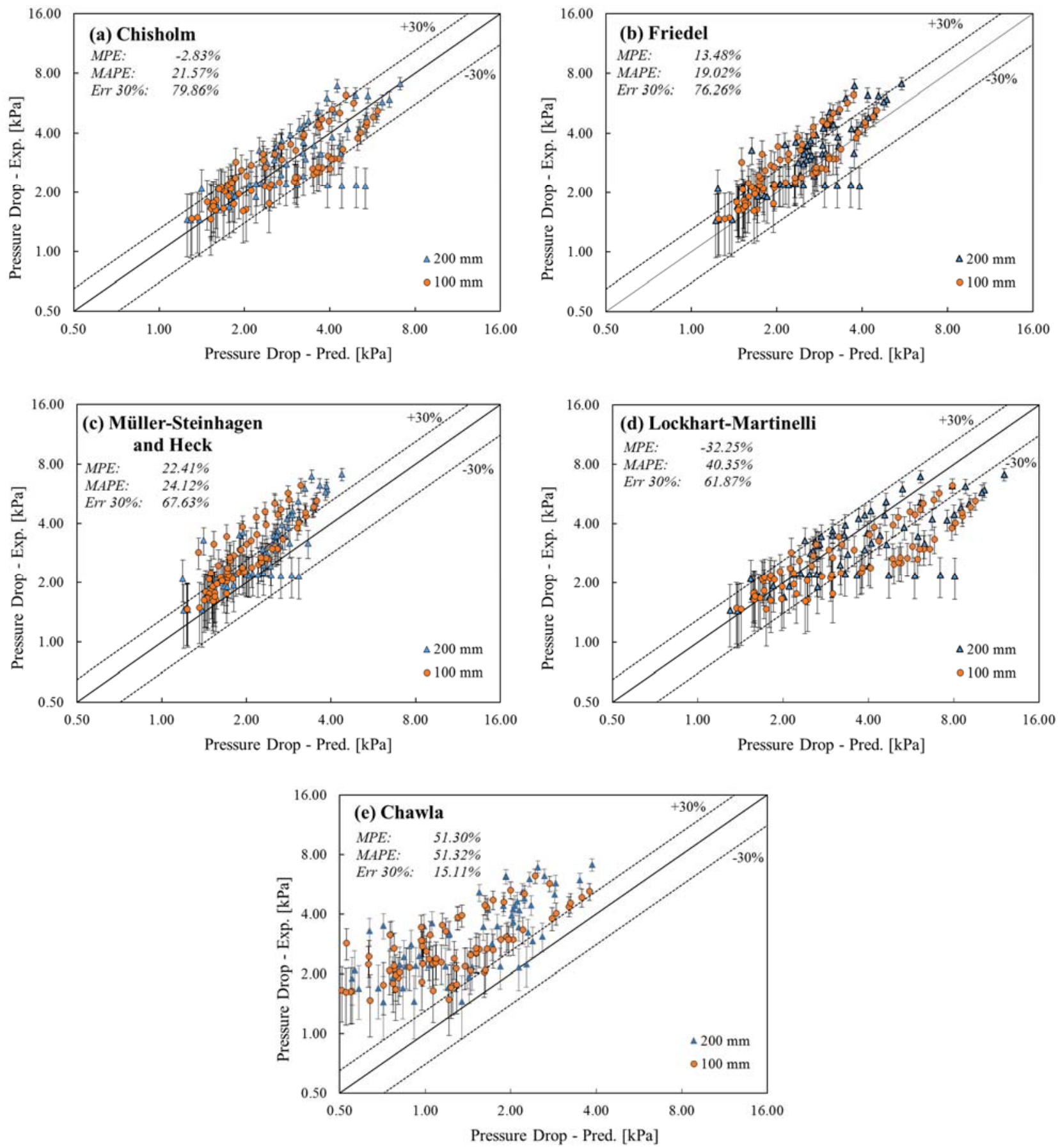

Fig. 12 -Total pressure drop predictions of subcooled points with the present methodology: (a) Chisholm 
International Journal of Heat and Mass Transfer 115 (2017) 1074-1090

http://dx.doi.org/10.1016/j.ijheatmasstransfer.2017.07.126

483

484

485

486

487

488

489

490

491

492

493

494

Tab. 13 - $100 \mathrm{~mm}$ results for saturated flow boiling points

\begin{tabular}{|c|c|c|c|c|c|}
\hline \multicolumn{5}{|c|}{$100 \mathrm{~mm}$ (24 points) } \\
\hline & \multicolumn{5}{|c|}{ Present methodology } \\
\hline $\begin{array}{c}\text { Subcooled } \\
\text { boiling model }\end{array}$ & $\begin{array}{c}\text { Lockhart- } \\
\text { Martinelli [15] }\end{array}$ & $\begin{array}{c}\text { Chisholm } \\
{[14]}\end{array}$ & $\begin{array}{c}\text { Chawla } \\
{[48]}\end{array}$ & $\begin{array}{c}\text { Friedel } \\
{[12]}\end{array}$ & $\begin{array}{c}\text { Müller-Steinhagen } \\
\text { and Heck [49] }\end{array}$ \\
\hline MPE & $-20.35 \%$ & $24.26 \%$ & $39.05 \%$ & $41.28 \%$ & $53.23 \%$ \\
\hline MAPE & $24.67 \%$ & $25.73 \%$ & $39.05 \%$ & $41.28 \%$ & $53.23 \%$ \\
\hline $\pm 30 \%$ & $75.00 \%$ & $54.17 \%$ & $41.67 \%$ & $20.83 \%$ & $0.00 \%$ \\
\hline
\end{tabular}

Tab. 12 - Results for saturated flow boiling points

\begin{tabular}{|c|c|c|c|c|c|}
\hline \multicolumn{5}{|c|}{ All points (84 points) } \\
\hline & \multicolumn{5}{|c|}{ Present methodology } \\
\hline $\begin{array}{c}\text { Subcooled } \\
\text { boiling model }\end{array}$ & $\begin{array}{c}\text { Lockhart- } \\
\text { Martinelli [15] }\end{array}$ & $\begin{array}{c}\text { Chisholm } \\
{[14]}\end{array}$ & $\begin{array}{c}\text { Chawla } \\
{[48]}\end{array}$ & $\begin{array}{c}\text { Friedel } \\
{[12]}\end{array}$ & $\begin{array}{c}\text { Müller-Steinhagen } \\
\text { and Heck [49] }\end{array}$ \\
\hline MPE & $-15.71 \%$ & $29.55 \%$ & $44.09 \%$ & $45.43 \%$ & $56.77 \%$ \\
\hline MAPE & $26.54 \%$ & $30.25 \%$ & $44.09 \%$ & $45.43 \%$ & $56.77 \%$ \\
\hline $\pm 30 \%$ & $70.24 \%$ & $44.05 \%$ & $15.48 \%$ & $14.29 \%$ & $0.00 \%$ \\
\hline
\end{tabular}

In the saturated zone, it is possible to use another correlation to best fit the experimental data. The chosen correlations are the same for subcooled flow boiling: Friedel [12], Lockhart-Martinelli [15], Chisholm [14], Chawla [48] and Müller-Steinhagen and Heck [49]. For the assessment, the vapor qualities and the actual void fraction are used, following the proposed methodology. As stated in Eq. (17), if the equilibrium quality is higher than the vapor quality, the equilibrium quality is used in the correlations, but the void fraction is always calculated with Eq. 15 regardless the kind of quality used. Tab. 12 summarizes all the results for the total pressure drops (only for the point when a saturated zone exists) and Tables 13 and 14 show the results for the $100 \mathrm{~mm}$ and $200 \mathrm{~mm}$ tubes, respectively.

\subsection{Saturated flow boiling assessment}


497 The saturated flow boiling pressure drops trends by using the proposed methodology, adopting different models, are shown in Fig. 13.

499
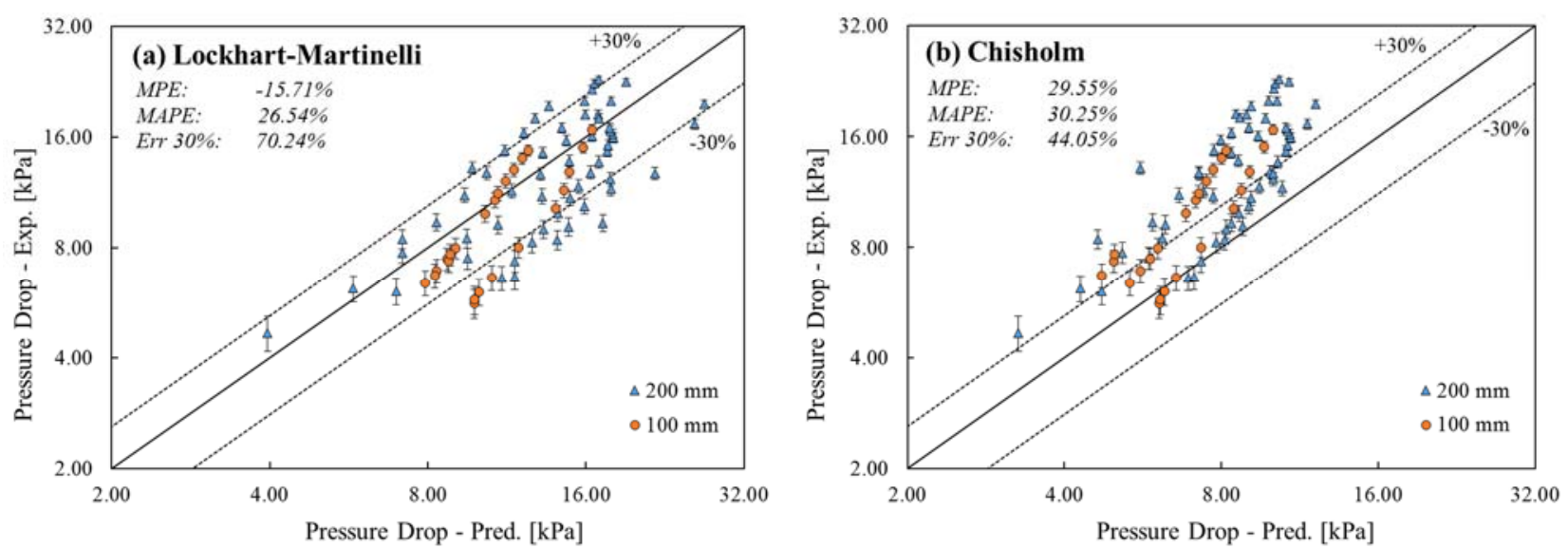

500
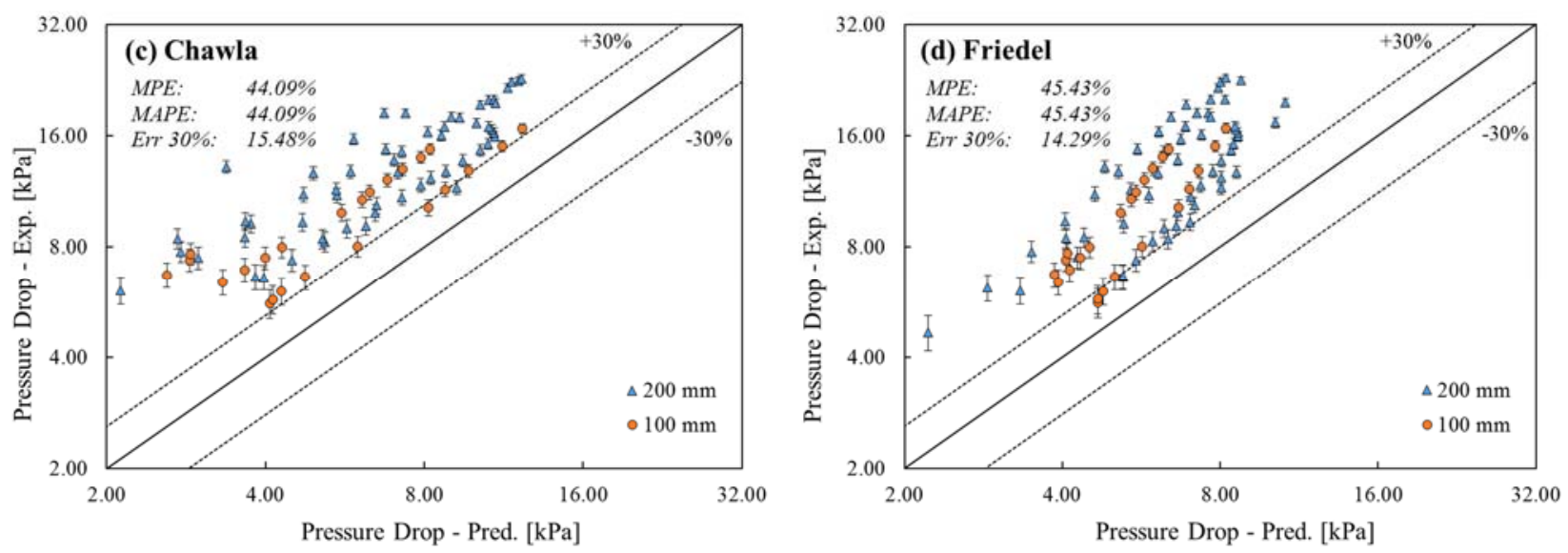

501

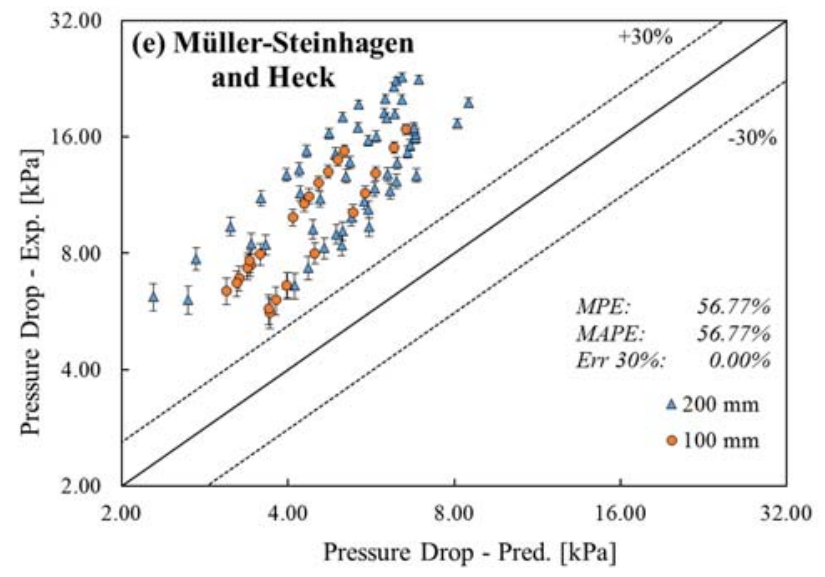

Fig. 13 -Total pressure drop predictions of saturated points: (a) Lockhart-Martinelli [15], (b) Chisholm [14],

(c) Chawla [48], (d) Friedel [12] and (e) Müller-Steinhagen and Heck [49]. 
506 Fig. 13 and the results summarized in Tab. 12 show how the predictions underestimate the experimental data in most of the correlations, suggesting the use of a higher void fraction in the channel. However, the Lockhart-Martinelli [15] correlation, that overestimated the data in subcooled flow boiling region, have a low error in saturated conditions; its MPE is - 15,71\%, the MAPE 26,54\% and $70,24 \%$ of the data have an error lower than $\pm 30 \%$. The second-best correlation is the Chisholm [14] one, with and MPE of 29,55\% a MAPE of 30,25\% and 44,05\% of the data with an error lower than $\pm 30 \%$. This suggests the use of the Lockhart-Martinelli [15] correlation to obtain a good prediction or the Chisholm [14] correlation in first approximation, as the latter provides good predictions in the subcooled boiling.

\subsection{Methodology assessment}

Merging the best results obtained from the single phase transient pressure drop obtained from Eq. (26), from Chisholm model [14] for the subcooled flow boiling and the best saturated flow boiling results, obtained with the Lockhart-Martinelli [15] model (both calculated with the void fraction of Eq. 15 and vapor quality of Eq. 17), the performance summarized in Tab. 15 has been obtained. The $100 \mathrm{~mm}$ tube get the best results with an MPE of $-5.25 \%$ a MAPE of $16.60 \%$ and $84.40 \%$ of the data with an error lower than $\pm 30 \%$. The global results, for both $100 \mathrm{~mm}$ and $200 \mathrm{~mm}$ channels, are quite good and near to the $100 \mathrm{~mm}$ tube results; the MPE is $-5.88 \%$, MAPE is $18.54 \%$ and $82.45 \%$ of the data has an error lower than $\pm 30 \%$.

Tab. 15 - Results for the proposed methodology

\begin{tabular}{|c|c|c|c|}
\hline & $100 \mathrm{~mm}$ & $200 \mathrm{~mm}$ & All points \\
\hline Points & 141 & 161 & 302 \\
\hline MPE & $-5.25 \%$ & $-6.43 \%$ & $-5.88 \%$ \\
\hline MAPE & $16.60 \%$ & $20.24 \%$ & $18.54 \%$ \\
\hline $\pm 30 \%$ & $84.40 \%$ & $80.75 \%$ & $82.45 \%$ \\
\hline
\end{tabular}

The total pressure drops trends obtained by using the proposed methodology, and adopting the model for single-phase in transition flow, Chisholm [14] for subcooled boiling and Lockhart-Martinelli [15] for saturated boiling, as described above, are shown in Fig. 14. It is also possible to use of Friedel [12] correlation for the subcooled zone, as the choice of using Chisholm [14] is due to the lower MPE joined to the largest number of data points predicted within $\pm 30 \%$. 


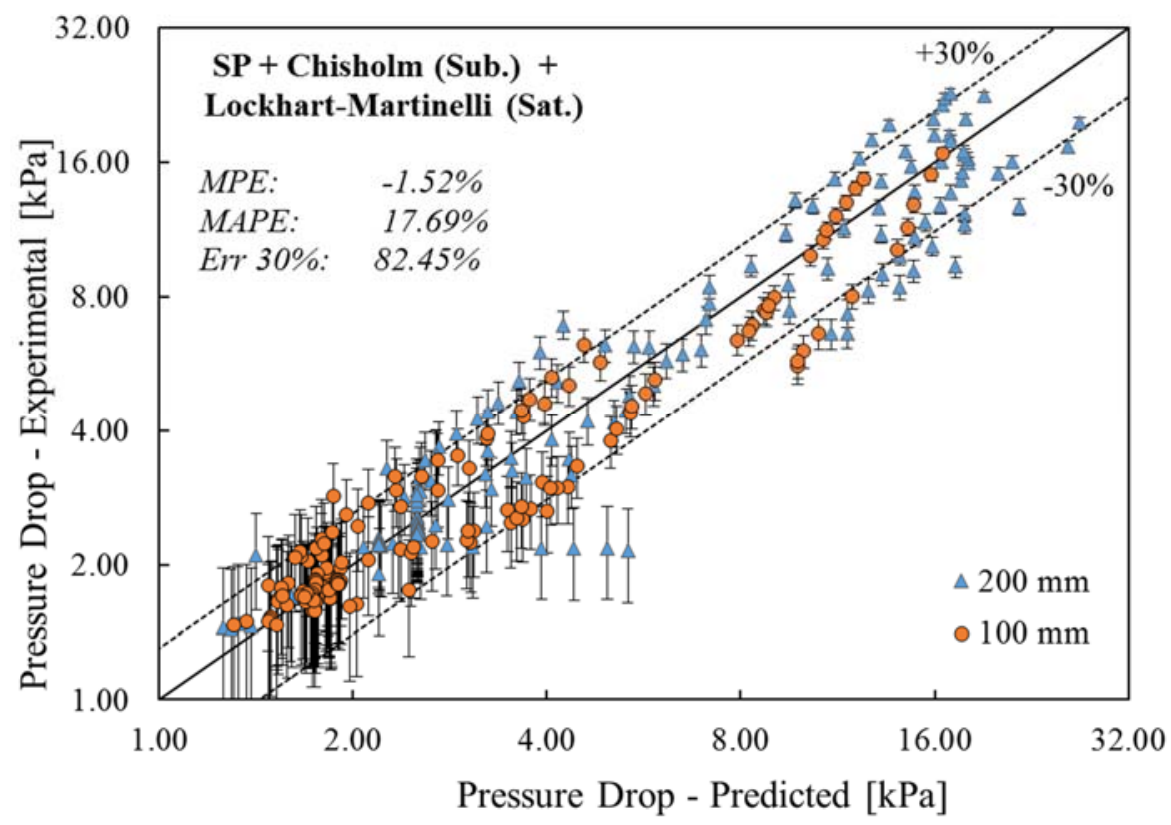

Fig. 14 -Total pressure drop predictions for the whole ENEA data base.

The average pressure drop (experimental) was $3.69 \mathrm{kPa}$ in the $100 \mathrm{~mm}$ channel, the minimum value was $1.47 \mathrm{kPa}$ and the maximum $16.74 \mathrm{kPa}$; for the $200 \mathrm{~mm}$ channel, the three values were: $6.87 \mathrm{kPa}$, $1.44 \mathrm{kPa}$ and $22.87 \mathrm{kPa}$, respectively.

\section{CONCLUSIONS}

The present study deals with a methodology to evaluate pressure drops in small tubes, using an ENEA data base for a mini tube with a diameter of $1 \mathrm{~mm}$ and two different lengths $(100$ and $200 \mathrm{~mm}$, respectively), and its validation when the flow is in transition conditions. The main features of the methodology are the capability to be used also in transition flow and in the use of non-equilibrium vapor quality instead of the equilibrium thermodynamic quality.

The calculation method includes single phase, subcooled and saturated boiling zones, identifying their boundaries. Employing a third order interpolation curve, the pressure drop for subcooled liquid in transition flow can be calculated. The methodology is based on the work of Delhaye et al. [28]. The model considers the fluid properties, the energy, mass and momentum conservation to predict the ONB, OSV points and a hyperbolic function is adopted to calculate the non-equilibrium vapor quality in the subcooled boiling region.

The vapor quality and void fraction are used in well-known pressure drop models, such as: Friedel [12], Chisholm [14], Chawla [48], Lockhart-Martinelli [15] and Müller-Steinhagen and Heck [49]. 
552 The results have been also compared with the correlations from Owens-Schrock [50] and Tong [51], 553 specific for subcooled flow boiling.

554 The best agreement with the ENEA experimental data has been obtained using the transition model 555 for the single-phase flow region, the Chisholm [14] model for the subcooled flow boiling region and 556 the Lockhart-Martinelli [15] for the saturated flow boiling region. The resulting MAPE is of 18,54\%, 557 a MPE of $-5,88 \%$ and $82,45 \%$ of the predicted points with an error lower than $30 \%$, in a data base of 558302 points. The results are very encouraging because none of the employed correlation was developed 559 specifically for the ENEA database or adapted on it, with the only exception of a small reduction of 560 the $\operatorname{Pr}$ number exponent (0.95 instead of 1) in the Frost and Dzakowic [31] correlation in the ONB 561 prediction. Further pressure drop correlations that can be used with the proposed methodology are 562 available in the literature. Moreover, all the methodology steps have been checked with an 563 "applicability model", proposed by Delhaye et al. [28], to assure the compatibility with the fluid and 564 ranges used in the experimental facility.

\section{Appendix -Summary of the methodology}

567 The total pressure drop in the tube can be calculated as:

$$
\int_{0}^{Z_{t}}\left(\frac{d p}{d z}\right)_{T}=\int_{0}^{Z_{O N B}}\left(\frac{d p}{d z}\right)_{f, S P}+\int_{Z_{O N B}}^{Z_{t}}\left(\frac{d p}{d z}\right)_{f, T P}+\int_{Z_{O N B}}^{Z_{t}}\left(\frac{d p}{d z}\right)_{a c c}+\int_{0}^{Z_{t}}\left(\frac{d p}{d z}\right)_{g}
$$

The gravitational contribution is neglected if the tube is horizontal $(\gamma=0)$ :

$$
\int_{0}^{Z_{t}}\left(\frac{d p}{d z}\right)_{g}=\int_{0}^{Z_{t}} \rho(Z) g \cdot d Z \sin \gamma
$$

571 The acceleration contribution is calculated in two-phase only, neglecting the density variation in the

$$
\int_{Z_{\text {ONB }}}^{Z_{t}}\left(\frac{d p}{d z}\right)_{a c c}=\int_{Z_{\text {ONB }}}^{Z_{t}} \frac{G^{2}}{\rho_{l}}\left(\frac{\rho_{l}}{\rho_{v}} \frac{x_{v}^{2}}{\alpha}+\left(\frac{\left(1-x_{v}\right)^{2}}{(1-\alpha)}-1\right)\right) \cdot d Z
$$

\section{A: Regions boundaries (ONB and Saturation points, Sect. 4)}

The single-phase region ends at the onset of nucleation boiling point, which can be identified as:

$$
Z_{O N B}=\frac{G c_{p l} D}{4} \cdot\left[\frac{\left(\left(T_{s a t}-T_{l, i n}\right)+\left(\Delta T_{s a t}\right)_{O N B}\right)}{Q}-\frac{1}{h_{l, \text { conv }}}\right]
$$


where the wall superheating at ONB is obtained from the modified Frost and Dzakowic correlation [31]:

$$
\left(\Delta T_{\text {sat }}\right)_{O N B}=\left(\frac{8 \sigma Q T_{\text {sat }}}{k_{l, s a t} H_{l v, s a t} \rho_{g}}\right)^{0.5} \operatorname{Pr}_{l}^{0.95}
$$

The saturation length is obtained by a simple energy balance:

$$
L_{s a t}=\frac{G \cdot D}{4 \cdot Q} \int_{T_{i n}}^{T_{s a t}} c_{p l} \cdot d T
$$

from which the saturation point is identified as $Z_{\text {sat }}=L_{\text {sat }}$, if $L_{\text {sat }}$ is less or equal than the tube length.

\section{B: Single-phase pressure drops (Sect. 6.1)}

The pressure drops in single phase are evaluated with:

$$
\int_{0}^{Z_{O N B}}\left(\frac{d p}{d z}\right)_{f, S P}=\int_{0}^{Z_{O N B}} f \cdot \frac{G^{2}}{2 D \rho_{l}} \cdot d Z
$$

where the friction factor $f$ is calculated through Eqs. (28) to (31) to consider the transition flow regime.

\section{C: Void fraction and actual vapour quality (Sect. 5)}

To calculate the acceleration and the two-phase frictional contributions, the evaluation of the void fraction is needed. It is calculated by the Lahey and Moody model [34]:

$$
\alpha=\frac{x_{v} \cdot \rho_{l} \cdot G}{C_{0}\left(x_{v} \cdot \rho_{l}+\left(1-x_{v}\right) \cdot \rho_{v}\right) G+V_{g} \cdot \rho_{l} \cdot \rho_{v}}
$$

The distribution parameter $C_{0}$ is evaluated by Eq. (22) and the weighted drift velocity by Eq. (25).

In the partial developed (between the ONB and the OSV points) and in the fully developed (from OSV to saturation) boiling regions, the non-equilibrium vapor quality is assumed, following Delaye et al. [28]:

$$
x_{v}(Z)=0.01 \xi\left\{x_{e q}(Z)-x_{e q}\left(Z_{O N B}\right)\left[\tanh \left(\left(\frac{x_{e q(Z)}}{x_{e q}\left(Z_{O N B}\right)}\right)-1\right)+1\right]\right\}
$$

where the equilibrium quality (negative in this zones) is evaluated by Eq. (16). The parameter $\xi$ is evaluated imposing the continuity at Zosv (Eq. (13)) with the quality calculated by Eqs. (18) to (21). 
603 The Chisolm model [14] provided the best agreement with ENEA data in the subcooled flow boiling 604 region. It can be used in the saturated region also, but the best agreement in saturation has been 605 provided by the Lockart-Martinelli model [15] (see Table 6 for the models' details).

606 607

\section{Nomenclature}

609 A actual value

610 Bd Bond number

611 Bo Boiling number

$612 \quad \mathrm{C}_{0} \quad$ distribution parameter

$613 \quad \mathrm{c}_{\mathrm{p}} \quad$ specific heat, $\mathrm{J} / \mathrm{kgK}$

614 C parameter in Lockhart-Martinelli correlation; calculated value

$615 \mathrm{D}$ tube diameter, $\mathrm{m}$

$616 \mathrm{Fr} \quad$ Froude number

$617 \mathrm{f}$ Fanning friction factor

$618 \mathrm{G}$ mass flux, $\mathrm{kg} / \mathrm{m}^{2} \mathrm{~s}$

$619 \mathrm{~g}$ gravitational acceleration, $9.806 \mathrm{~m} / \mathrm{s}^{2}$

$620 \quad \mathrm{H}_{\mathrm{lv}} \quad$ latent heat, $\mathrm{J} / \mathrm{kg}$

$621 \mathrm{H}$ enthalpy, $\mathrm{J} / \mathrm{kg}$

$622 \mathrm{~h}$ heat transfer coefficient, $\mathrm{W} / \mathrm{m}^{2} \mathrm{~K}$

$623 \mathrm{k}$ thermal conductivity, $\mathrm{W} / \mathrm{mK}$

$624 \mathrm{~L}$ tube length, $\mathrm{m}$

$625 \mathrm{~N}$ number of data points

$626 \mathrm{n}$ coefficient

627 Pr Prandtl number

$628 \mathrm{p}$ pressure, $\mathrm{Pa}$

$629 \mathrm{Q}$ heat flux, $\mathrm{W} / \mathrm{m}^{2}$

$630 \mathrm{Re} \quad$ Reynolds number

$631 \mathrm{~S}$ suppression factor

$632 \mathrm{~T}$ temperature, $\mathrm{K}$
$633 \quad \mathrm{~V}_{\mathrm{g}}$

$634 \mathrm{We}$

$635 \quad X_{\mathrm{tt}}$

$636 \mathrm{x}$

$637 \quad \mathrm{Y}$

$638 \mathrm{Z}$

weighted drift velocity, $\mathrm{m} / \mathrm{s}$

Weber number

Lockhart-Martinelli parameter quality Chisholm correlation coefficient axial coordinate (stream-wise)

639 Greek symbols

$640 \alpha \quad$ void fraction

$641 \Gamma \quad$ volumetric flow rate, $\mathrm{m}^{3} / \mathrm{s}$

$642 \mu \quad$ dynamic viscosity, Pa s

$643 \xi \quad$ convergence parameter

$644 \rho \quad$ density, $\mathrm{kg} / \mathrm{m}^{3}$

$645 \sigma \quad$ surface tension, $\mathrm{N} / \mathrm{m}$

$646 \varphi \quad$ two-phases multiplier 
648 conv convective

649 eq equilibrium

650 F friction

$651 \mathrm{H}$ heated

652 in inlet

653 lam laminar

654 lo liquid only

6551 liquid

656 out outlet

$657 \Delta \mathrm{P} \quad$ pressure drop

658 sat saturated

659 sub subcooled

660 SP single-phase

661 TP two-phase

662 turb turbulent

$663 \mathrm{t}$ total

$664 \mathrm{v}$ vapor

665 vo vapor only

666 w wall

$667 \quad \mathrm{z}$ axial

668

669

670

671

672

673

674

675

676

677

678

679

680

681

682

683

684

685

686

687

688

689

690

691

692

693

694

695

\section{Acronyms}

\section{References}

MAPE Mean Average Percentage Error

MPE Mean Percentage Error

ONB Onset Nucleate Boiling point

OSV Onset Significant Void point

PDB Partial Developed Boiling region

FDB Full Developed Boiling region

[1] S.M. You, T.M. Simon, A. Bar-Cohen, Experiments on Nucleate Boiling Heat Transfer with a HighlyWetting Dielectric Fluid: Effects of Pressure, Subcooling and Dissolved Gas Content, Cryogenic and Immersion Cooling of Optics and Electronic Equipment, HTD-Vol. 131 (1990), 45-52.

[2] M. Caira, G. Caruso, A. Naviglio, A correlation to predict CHF in subcooled flow boiling, Int Comm. in Heat and Mass Transfer, Vol. 22 (1995), 35-45.

[3] A.M. Jacobi, S.S. Mehendale, R.K. Shah, Fluid flow and heat transfer at micro- and meso-scales with application to heat exchanger design, Applied mechanics review, 53 (2000), 175-193.

[4] G. Kandlikar, Scale effect on flow boiling heat transfer in microchannels: a fundamental perspective. International journal of thermal sciences, 49 (2010), 1073-1085.

[5] P. Cheng and H.Y. Wu. Mesoscale and microscale phase-change heat transfer. Advances in heat transfer (2006), 39:469-573.

[6] M.B. Ould Didi, N. Kattan, J.R. Thome, Prediction of Two-Phase Pressure Gradients of Refrigerants in Horizontal Tubes, International Journal of Refrigeration 25 (2002), 935-947.

[7] H. Muller-Steinhagen, K. Heck. A simple friction pressure drop correlation for two-phase flow in pipes. Chem. Eng. Processing 20 (1986), 297-308.

[8] R. Gronnerud, Investigation of liquid hold up, flow resistance and heat transfer in circulation type evaporators, Part IV: two phase flow resistance in boiling refrigerants, Annex 1972-1, Bull Del'Inst. Du Froid (1972). 
International Journal of Heat and Mass Transfer 115 (2017) 1074-1090

http://dx.doi.org/10.1016/j.ijheatmasstransfer.2017.07.126

[9] G. Ribatski, L. Wojtan, J.R. Thome, An analysis of experimental data and prediction methods for twophase frictional pressure drop and flow boiling heat transfer in micro-scale channels. Experimental thermal and fluid science 31-1 (2006), 1-19.

[10] M. Zhang, R.L. Webb, Correlation of two-phase friction for refrigerants in small-diameter tubes, Exp. Thermal Fluid Sci. 25 (2001) 131-139.

[11] K. Kuwahara, S. Koyama, K. Kazari, Experimental study of flow boiling of HFC134a in a multi-port extruded tube, ICMM2004, Rochester, New York, USA (2004).

[12] L. Friedel, Improved friction pressure drop correlations for horizontal and vertical two-phase pipe flow, European Two-Phase Flow Group Meeting, Ispra, Italy, Paper E2 (1979).

[13] G.M. Lazarek, S.H. Black, Evaporative heat transfer, pressure drop and critical heat flux in a small vertical tube with R-113, Int. J. Heat Mass Transfer 25 (1982) 945-960.

[14] D. Chisholm, A theoretical basis for the Lockhart-Martinelli correlation for two-phase flow, Int. J. Heat Mass Transf. 10-18 (1967), 1767-1778.

[15] R.W. Lockhart, R.C. Martinelli, Proposed correlation of data for isothermal two-phase two-component flow in pipes, Chem. Eng. Progr. 45-1 (1949), 39-48.

[16] W. Qu, I. Mudawar, Measurement and prediction of pressure drop in two-phase micro-channel heat sinks, int. J. Heat mass transf. 46 (2003), 2737-2753.

[17] J. Lee, I. Mudawar, Two-phase flow in high-heat-flux micro-channel heat sink for refrigeration cooling applications: part I - pressure drop characteristics, Int. J. Heat mass transf. 48 (2005), 928-940.

[18] P.S. Lee, S.V. Garimella, Saturated flow boiling heat transfer and pressure drop in silicon microchannel arrays, Int. J. Heat mass transf. 51 (2008), 789-806.

[19] K. Mishima, T. Hibiki, Some characteristics of air-water two-phase flow in small diameter vertical tubes, Int. J. Multiphase Flow 22 (1996) 703-712

[20] M.B. Bowers, I. Mudawar, Two-phase electronic cooling using mini-channel and micro-channel heat sinks: part 1 - Design Criteria and Heat Diffusion Constraints, J. Electron. Packag. 116 (1994), 290297.

[21] M.B. Bowers, I. Mudawar, Two-phase electronic cooling using mini-channel and micro-channel heat sinks: Part 2- flow rate and pressure drop constraints, J. Electron. Packaging 116 (1994) 298-305.

[22] S.G. Kandlikar, M.E. Steinke, S. Tian, L.A. Campbell, High-speed photographic observation of flow boiling of water in parallel mini-channels, Proceedings of 35th National Heat Transfer Conference, ASME, Anaheim, CA (2001), 675-684.

[23] G. Hetsroni, A. Mosyak, Z. Segal, G. Ziskind, A uniform temperature heat sink for cooling of electronic devices, Int. J. Heat Mass Transfer 45 (2002), 3275- 3286.

[24] T.N Tran, M.-C Chyu, M.W Wambsganss, D.M France, Two-phase pressure drop of refrigerants during flow boiling in small channels: an experimental investigation and correlation development, International Journal of Multiphase Flow 26-11 (2000), Pages 1739-1754.

[25] S.M. Kim, I. Mudawar, Universal approach to predicting two-phase frictional pressure drop for mini/micro-channel saturated flow boiling, Int. J. Heat Mass Transf. 58 (1-2) (2013), 718-734.

[26] L. Saraceno, G.P. Celata, M. Furrer, A. Mariani, G. Zummo, Flow boiling heat transfer of refrigerant FC-72 in microchannels, International Journal of Thermal Sciences 53 (2012), 35-41.

[27] L. Gugliermetti, G. Caruso, L. Saraceno, G. Zummo, G.P. Celata, Saturated flow boiling of FC-72 in $1 \mathrm{~mm}$ diameter tube, International Communications in Heat and Mass Transfer 75 (2016), 115-123.

[28] J. M. Delhaye, F. Maugin, J.M. Ochterbeck, Void fraction predictions in forced convective subcooled boiling of water between 10 and $18 \mathrm{MPa}$, International Journal of Heat and Mass Transfer 47 19-20 (2004), 4415-4425.

[29] J.M. Kay, R.M. Nedderman, An Introduction to Fluid Mechanics and Heat Transfer, third ed., Cambridge University Press, Cambridge (1974), 134-144.

[30] G. R Celata, M. Cumo, and T. Setaro Hysteresis phenomena in subcooled flow boiling of well-wetting fluids, Experimental Heat Transfer 5-4 (1992), 54-75.

[31] W. Frost, G.S. Dzakowic, An extension of the method of predictive incipient boiling on commercially finished surfaces, ASME-AIChE Heat Transfer Conference, Seattle (1967). 
International Journal of Heat and Mass Transfer 115 (2017) 1074-1090

http://dx.doi.org/10.1016/j.ijheatmasstransfer.2017.07.126

[32] P. Saha, N. Zuber, Point of net vapor generation and vapor void fraction in subcooled boiling, Fifth Int. Heat Transfer Conf., Tokyo, Paper B4.7 (1974).

[33] N. Zuber, J.A. Findlay, Average volumetric concentration in two phase flow systems, J. Heat Transfer 87 (1965), 453-467.

[34] R.T. Lahey Jr., F.J. Moody, The Thermal Hydraulics of a Boiling Water Nuclear Reactor, American Nuclear Society, LaGrange Park (1977).

[35] S. Levy, Forced convection subcooled boiling-prediction of vapor volumetric fraction, Int. J. Heat Mass Transfer 19 (1967), 99-113.

[36] P. Griffith, J.A. Clark, W.M. Rohsenow, Void volumes in subcooled boiling systems, ASME Paper 58-T-19, New York (1958).

[37] H. Nabizadeh, Ubertragungsgesetze fur den Dampfvolum-enanteil zwischen Freon und Wasser, Kolloquium uber Aehnlichkeitsgesetze in Zweiphasenstromungen, Institut fur Verfahrenstechnik der T.U. Hannover (1980).

[38] G.E. Dix, Vapor Void Fractions for Forced Convection with Subcooled Boiling at Low Flow Rate, Ph.D. Thesis, University of California (1971).

[39] S.M. Kim, I. Mudawar, Consolidated method to predicting pressure drop and heat transfer coefficient for both subcooled and saturated flow boiling in micro-channel heat sinks, International Journal of Heat and Mass Transfer, Volume 55 13-14 (2012), 3720-3731.

[40] M. Margulis, E. Shwageraus, Extending Two-Phase Capabilities of Thermal-Hydraulic Module in BGCore, Reactor Physics and Technology II (In memory of Dr. Uri Mintzer) (2014).

[41] V.S. Osmachkin, V. Borisov, Pressure drop and heat transfer for flow boiling water in vertical rod bundles, Paper B4.9, IVth International Heat Transfer Conference Paris-Versailles (1970).

[42] W.R. Brownlie, Reexamination of Nikuradse roughness data, Journal of the Hydraulics DivisionASCE, 107-1 (1981), 115-119.

[43] N.S. Cheng, Y.M. Chiew, Modified logarithmic law for velocity distribution subjected to upward seepage, Journal of Hydraulic Engineering, ASCE 124-12 (1998), 1235-1241.

[44] P.M. Ligrani, R.J. Moffat, Structure of Transitionally Rough and Fully Rough Turbulent BoundaryLayers, Journal of Fluid Mechanics 162 (1986), 69-98.

[45] M. S. Yalin, A.M.A.F. Da Silva, Fluvial processes, IAHR, Delft, Netherlands (2001).

[46] N.S. Cheng, Formulas for friction factor in transitional regions, Journal of Hydraulic Engineering, ASCE 134-9 (2008)., 1357-1362.

[47] C.F. Colebrook, Turbulent flow in pipes with particular reference to the transition region between the smooth and rough pipe laws, Proceedings of the Institution of Civil Engineers, 12 (1939), 393-422.

[48] J.M. Chawla, Wärmeübergang und Druckabfall in Waagerechten Rohren bei der strömung von Verdampfenden Kältemitteln, VDI-Verlag (1967).

[49] H. Müller-Steinhagen, K. Heck, A simple friction pressure drop correlation for two-phase flow in pipes, Chem. Process Engineering, Vol. 20 (1986), pp. 297-308.

[50] W.L. Owens, V.E. Schrock, Local pressure gradients for subcooled boiling of water in vertical tubes, ASME Paper No. 60-WA-249 (1960).

[51] W. Tong, A.E. Bergles, M.K. Jensen, Pressure drop with highly subcooled flow boiling in smalldiameter tubes, Exp. Therm. Fluid Sci. 15 (1997), 202-212.

[52] L. Friedel, Momentum exchange and pressure drop in two-phase, NATO Advanced Study Institute, Istanbul, Turkey (1975) (Also Appendix B, P. Whalley "Boiling Condensation and Gas-Liquid Flow", Oxford, 1987).

[53] C. Tribbe, H. Müller-Steinhagen. An Evaluation of the Performance of Phenomenological models for Predicting Pressure Gradient during Gas-Liquid Flow in Horizontal Pipelines, Int. J. Multiphase Flow 26 (2000), 1019-1036. 